DOUGLAS DE SOUSA COSTA

\title{
PAPEL DA AUTOFAGIA NA MODULAÇÃO DA IMUNOPATOGÊNESE DA MALÁRIA PLACENTÁRIA
}

Dissertação apresentada ao Programa de Pós-Graduação em Biologia da Relação Patógeno-Hospedeiro do Instituto de Ciências Biomédicas da Universidade de São Paulo para obtenção do Título de Mestre em Ciências

Área de concentração: Parasitologia

Orientador: Prof. Dr. Cláudio Romero Farias Marinho

Versão Corrigida

São Paulo

2018 


\section{RESUMO}

Costa, DS. Papel da Autofagia na Modulação da Imunopatogênese da Malária Placentária. [Dissertação (Mestrado em Parasitologia)]. São Paulo: Instituto de Ciências Biomédicas da Universidade de São Paulo; 2018

A malária representa um dos mais importantes problemas de saúde pública da atualidade, afetando milhões de pessoas ao redor do globo, incluindo mulheres em idade reprodutiva. Todos os anos, pelo menos 125 milhões de gestantes encontramse expostas à doença, a qual é associada a um elevado risco de morte para a mãe e para o feto. A malária placentária é caracterizada pelo sequestro de parasitos na placenta, contribuindo para o desenvolvimento de anemia materna, restrição do crescimento intrauterino e diminuição da viabilidade fetal. Nesse cenário, a disrupção da homeostase no ambiente placentário tem um papel crucial, e processos que visam sua recuperação são ativados. A autofagia consiste em um desses processos e é fundamental para a sobrevivência da célula em situações de estresse. Ela regula a homeostase citoplasmática, e também está envolvida na resposta a doenças infecciosas e na modulação do sistema imunológico. Por outro lado, é sabido que existem várias moléculas de sinalização relacionadas ao sistema imune que regulam a autofagia nos mais diversos tipos celulares, como por exemplo, nas células trofoblásticas. Na placenta estes mecanismos de sinalização têm uma função importante na adaptação a insultos de conhecido efeito deletério para gravidez. Assim, este trabalho teve como objetivo estudar a participação da autofagia na patogenia da malária placentária, utilizando para isso um modelo murino de infecção. Foram utilizadas fêmeas C57BI/6 prenhes infectadas por Plasmodium berghei NK65 GFP no $13^{\circ}$ dia de prenhez. Posteriormente, os fetos foram retirados e pesados, e as placentas foram isoladas para análises histopatológicas. Além disso, foram realizadas quantificações por western blotting dos marcadores de indução e fluxo da via autofágica. Os achados do presente trabalho indicam que a infecção nas fêmeas prenhes induziu o baixo peso na prole e contribuiu para importantes modificações histológicas na placenta. Além disso, foi observada uma diminuição da região do espongiotrofoblasto associada a um aumento do labirinto, além de um significativo espessamento das barreiras interhemais. Foi detectada uma redução na expressão do transportador de aminoácidos Slc16A3. Observou-se ainda, em placentas de animais infectados, um aumento na indução da autofagia, caracterizado pela maior expressão de Beclin-1. Acompanhando estas observações, verificou-se também uma redução dos níveis de LC3-II. Esses resultados mostram uma modulação das proteínas autofágicas durante a malária placentária murina, propiciando novas perspectivas para o estudo deste processo biológico na infecção causada por Plasmodium spp. Além disso, nossos dados apontam para a importância de novos estudos envolvendo as adaptações placentárias na busca de tratamentos alternativos para a malária gestacional.

Palavras-chave: Plasmodium berghei. Autofagia. Inflamação. Placenta. Malária placentária. Malária gestacional. 


\begin{abstract}
Costa, DS. Role Autophagy in the Modulation of Immunopathogenesis of Placental Malaria. [Dissertation (Master in Parasitology)]. São Paulo: Instituto de Ciências Biomédicas da Universidade de São Paulo; 2018
\end{abstract}

Malaria is one of the most important public health problems worldwide. Annually, at least 125 million pregnant women are at risk of developing malaria, which is associated to increased maternal and fetal mortality. These women may develop placental malaria, which is characterized by the sequestration of the parasite inside the placenta, contributing to maternal anemia, intrauterine growth restriction and decreased fetal viability. Autophagy is a key process for cell survival, and a regulator of cytoplasmic homeostasis, being involved in infectious diseases, neurodegenerative diseases and cancer, also playing a role in the development of the embryo and in the modulation of the immune system. It is known that several signaling molecules related to the immune system regulate autophagy in the great majority of cells, including trophoblasts, in which this signaling mechanism has a pivotal role in their adaptation to several factors that may bring deleterious consequences to pregnancy. This work aimed to study the participation of autophagy in the pathogenesis of placental malaria. In this context, we have used a murine model of infection, which consists of an infection of $\mathrm{C} 57 \mathrm{Bl} / 6$ pregnant mice at gestational day 13 with the parasite Plasmodium berghei NK65GFP. At gestational day 19 , placentas were isolated for histopathological analysis and protein quantification of induction (ULK-1 and Beclin-1) and flux (LC3) markers for autophagy by western blotting. Our findings have shown that infection of pregnant mice lead to reduced fetal weight and contributed to important histologic changes in the placenta. Additionally, we have observed a decrease in the spongiotrophoblast region, which was associated with an increase of the labyrinth region, as well as an augmented thickening of the interhaemal barriers. In parallel, we have also observed a reduction in the expression of the amino acid transporter Slc16A3. Strikingly, we have shown that there is an increased induction of autophagy in placentas from infected mice, characterized by the augmented Beclin-1. In accordance, we have also observed a reduction of LC3-II levels. Altogether, our results showed a modulation of autophagic proteins during murine placental malaria, opening new perspectives for the study of this biological process during the infection caused by Plasmodium spp.and encouraging new studies and methodologies for the treatment of placental malaria.

Key words: Plasmodium berghei. Autophagy. Inflammation. Placenta. Placental malaria. Gestational malaria. 


\section{INTRODUÇÃO}




\subsection{Malária: uma breve revisão histórica}

A malária tem acompanhado a humanidade praticamente por toda a sua história(1), provavelmente apresentando maior influência nas populações humanas do que qualquer outra doença infecciosa. As primeiras referências históricas em relação aos sintomas peculiares da doença foram descritas na China há aproximadamente 5.000 anos, pelo imperador Huang Ti no seu estudo médico, Nei Ching (A Lei da Medicina)(1,2). Já a descrição detalhada dos tipos de febres associados à malária e do aumento do baço nos pacientes remete ao século $\mathrm{V}$ a.C., realizada pelo grego Hipócrates. O nome malária provém de mal aire (mau ar, em italiano), pois se acreditava que os sintomas inerentes à enfermidade eram devido aos locais com ar insalubre. Somente após as descobertas de Louis Pasteur sobre a teoria dos germes, tornou-se mais aceita a hipótese de que a doença poderia ser causada a partir de infecções microbianas(1).

O agente causador da malária foi descoberto por Charles Louis Alphonse Laveran (1845-1922) no final do século XIX(3). Laveran era um médico que serviu ao exército francês durante o período da guerra Franco-Prussiana, quando a infecção foi responsável por dizimar milhares de soldados. Seus estudos clínicopatológicos da doença forneceram dados minuciosos acerca da histologia da malária cerebral. A observação da presença do parasito nos órgãos e no sangue dos seus pacientes propiciou a descoberta de dois estágios da doença, chamados de malária grave e crônica; nas quais o único elemento em comum era a presença de grânulos escuros com movimentos ameboides, por isso denominados Oscillaria malariae. Atualmente, é sabido que esses grânulos são de hemozoína, o produto da digestão da hemoglobina pelo parasito $(1,4)$.

Diferindo de Laveran, que acreditava na existência de apenas uma espécie do parasito, denominado Oscillaria malariae, Camillo Golgi encontrou duas formas da doença: uma com periodicidade terçã (ciclo de 48 horas) e outra com periodicidade quartã (ciclo de 72 horas). Suas observações demonstraram que não só essas formas distintas produziam quantidades diferentes de merozoítos, como também a febre tinha ocorrência simultânea com a ruptura e liberação destes merozoítos na corrente sanguínea. Apenas alguns anos mais tarde, os cientistas italianos Giovanni Batista Grassi e Raimondo Filetti adotaram pela primeira vez os nomes Plasmodium vivax e Plasmodium malariae, para dois dos parasitos que afetam os seres 
humanos, enquanto o parasito da malária terçã maligna foi nomeado como Plasmodium falciparum pelo cientista norte-americano William $\mathrm{H}$. Welch $(1,4,5)$.

Identificados os parasitos causadores da doença, iniciava-se 0 questionamento de como estes infectariam os seres humanos Laveran e Mason levantaram a hipótese de que os mosquitos eram os agentes disseminadores da malária, a qual foi validada, em 1897, por Ronald Ross. Enquanto examinava o tecido digestório de um mosquito anofelino que havia se alimentado de um paciente com malária, Ronald Ross encontrou o parasito, provando o papel do mosquito Anopheles na transmissão da malária para seres humanos. Ross continuou os seus estudos usando como modelo experimental a malária em aves e, em 1898, demonstrou que os mosquitos poderiam ser vetores para o plasmódio aviário. Posteriormente, o referido pesquisador evidenciou que os parasitos poderiam se desenvolver no mosquito e migrar para suasglândulas salivares possibilitando a reinfecção de outras aves picadas. Mais tarde, os cientistas Amico Bignami, Giuseppe Bastianelli e Giovanni Batista Grassi conseguiram demonstrar o ciclo de vida completo de Plasmodium falciparum, $P$. vivax e $P$. malariae, usando mosquitos (da espécie Anopheles claviger) que se alimentaram do sangue de pacientes com malária e, em seguida, foram utilizados para picar outros pacientes saudáveis, os quais, semanas depois, também desenvolveram malária(1,2,6).

Após a descoberta do vetor do parasito causador da malária e a compreensão do seu ciclo de vida, muitas medidas foram tomadas para tentar erradicar a doença do mundo. Pelofato da doença ter dizimado um grande número de soldados nas duas grandes guerras e de representar um importante empecilho para aexpansão territorialista das nações europeias para regiões tropicais, vários países uniram-se para desenvolver medidas profiláticas e drogas antimaláricas(7).

A malária foi essencial para o desenvolvimento cientifico em relação ao uso de drogas sintéticas, sendo a doença mais estudada em meados do século $X X(7)$. Nas décadas de 50 e 60, a Organização Mundial da Saúde (OMS) liderou um programa de erradicação da malária e, entre muitas drogas testadas, a cloroquina foi a que se mostrou mais eficiente. No entanto, ao mesmo tempo em que havia urgência na erradicação da doença houve também o uso indiscriminado da cloroquina. Isto favoreceu a seleção de cepas do parasito resistentes à droga, o que comprometeu sua estratégia de erradicação e aumentou a necessidade do desenvolvimento de novas drogas mais potentes(8). 
Atualmente, várias organizações estão à procura de uma vacina que, em conjunto com métodos já eficientes de intervenção, poderá no futuro controlar e até mesmo erradicar a malária no mundo(9).

\subsection{Epidemiologia da malária}

Transmitido pela picada da fêmea de mosquitos do gênero Anopheles spp., o parasito intracelular obrigatório do gênero Plasmodium spp. é o agente causador da malária em diversas espécies de mamíferos, aves e répteis(10). Existem aproxidamente 25 espécies de anofelinos conhecidas por serem bons vetores do Plasmodium sp. Possuem rápida geração de descendentes e são resistentes às mudanças climáticas e ambientais, sendo capazes de sobreviver em ambientes tropicais e com abundante densidade populacional, assim, favorecendo a disseminação do parasito(11).

Dentre as muitas espécies do parasito, as que são conhecidas por infectarem os seres humanos são: Plasmodium malariae, Plasmodium ovale, Plasmodium vivax, Plasmodium falciparum, Plasmodium knowlesi e Plasmodium cynomolgi(12,13). A malária causada por $P$. falciparum é responsável pela forma mais grave da doença, acarretando as maiores taxas de mortalidade, principalmente no continente africano(14).

Considerada como um grave problema de saúde pública, a malária assola milhões de pessoas, afetando, sobretudo, as populações pobres residentes em áreas tropicais e subtropicais(14). Segundo o relatório disponibilizado pela Organização Mundial da Saúde (OMS) em 2016, houve aproximadamente 216 milhões de casos em todo o planeta, e cerca de 445 mil mortes foram registradas. De todos esses casos, cerca de 90\% ocorreram no continente africano; seguido de $7 \%$ dos relatos ocorridos no sudeste asiático e $2 \%$ na região leste do mediterrâneo (Fig. 1)(15).

Apesar da redução no número de casos, entre 2014 e 2016, ocorreu um substancial aumento da doença na América do Sul (Brasil e Venezuela, principalmente). Hoje em dia quase metade da população mundial (3,3 bilhões de pessoas) reside em áreas de risco de transmissão da malária. Os países africanos (região subsaariana) são os principais em taxas de mortalidade, com a República Democrática do Congo e Nigéria registrando $35 \%$ do total de mortes causadas pela 
doença em todo o mundo. A redução da incidência de malária tem sido letárgica nessas regiões, em relação a outros países $(15,16)$.

\section{Figura 1 - Países endêmicos para a malária}

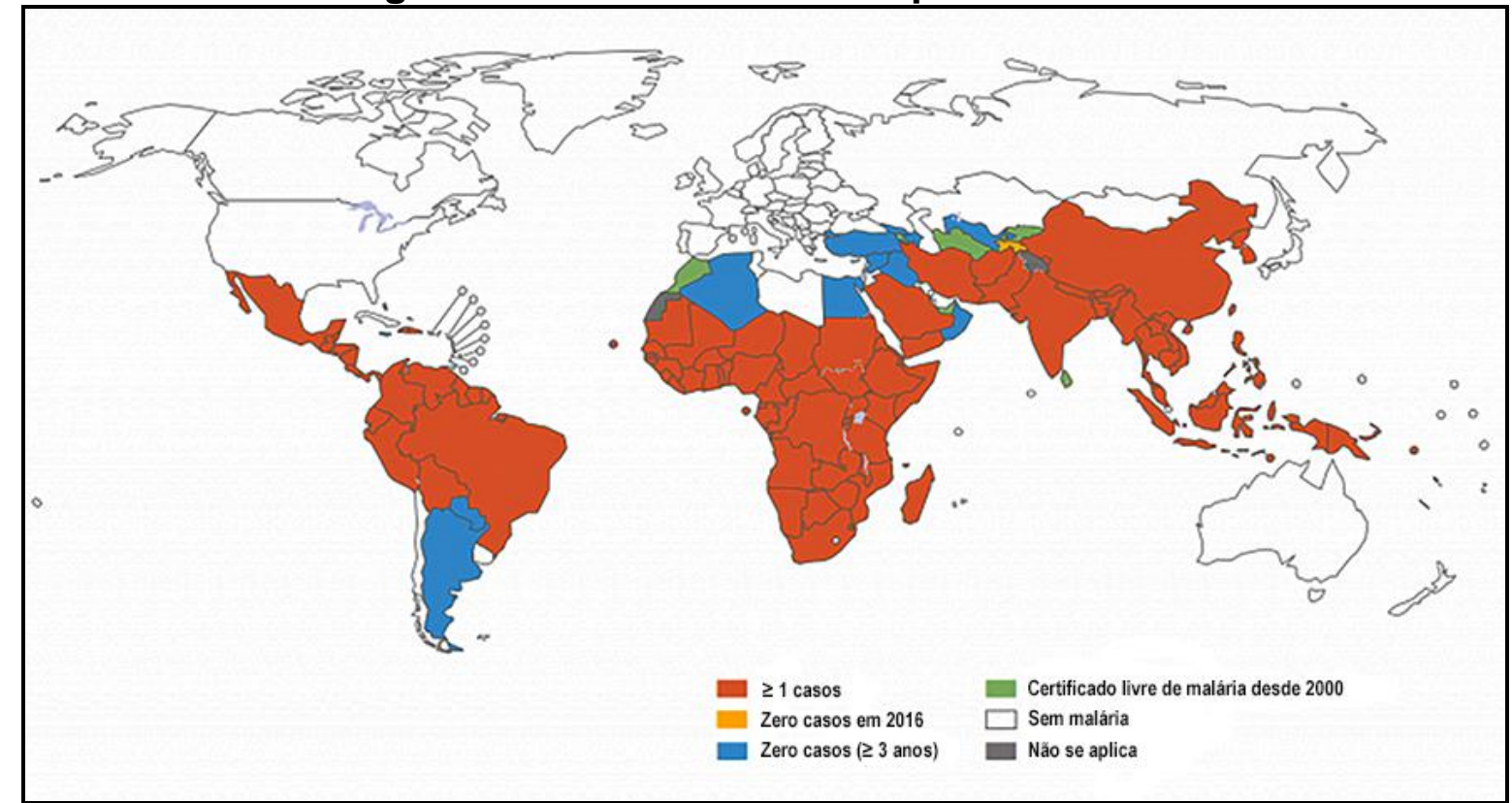

llustração mostrando as taxas de incidência de malária, por país, do ano de 2000 até 2016. Destacase o grande número de países que estão em risco de transmissão para doença (modificado de WHO, 2017)(15).

Na América do Sul, a malária acomete mais de um milhão de pessoas anualmente nos países situados na Região Amazônica (17). No Brasil 99\% dos casos de malária concentram-se na Região Amazônica, e cerca de 45\% destes ocorrem nos estados do Acre e Amazonas. Segundo a OMS, em 2016 o país concentrava $18 \%$ dos casos de malária em comparação aos outros países americanos (15)...

A Amazônia legal, formada pelos estados do Acre, Amapá, Amazonas, Maranhão, Mato Grosso, Pará, Rondônia, Roraima e Tocantins, concentra a maioria dos relatos de malária e é considerada uma região endêmica no país. Dados do Ministério da Saúde mostram que em 2014143.552 casos foram notificados nesta região. Das seis espécies já conhecidas por causarem malária em seres humanos, no Brasil três delas estão associadas a casos autóctones: Plasmodium vivax, Plasmodium falciparum e Plasmodium malariae. Os casos de infecção por $P$. vivax são prevalentes no Brasil, seguidas por $P$. falciparum, com respectivamente $84 \%$ e $16 \%$ das notificações em 2014(17,18).O Estado do Amazonas contribui com o maior 
número de ocorrências (47\%), seguido pelo Estado do Acre (22\%) destes, 42\% são por P. falciparum (Fig. 2)(18).

Figura 2 - Notificações de casos de malária na Região Amazônica

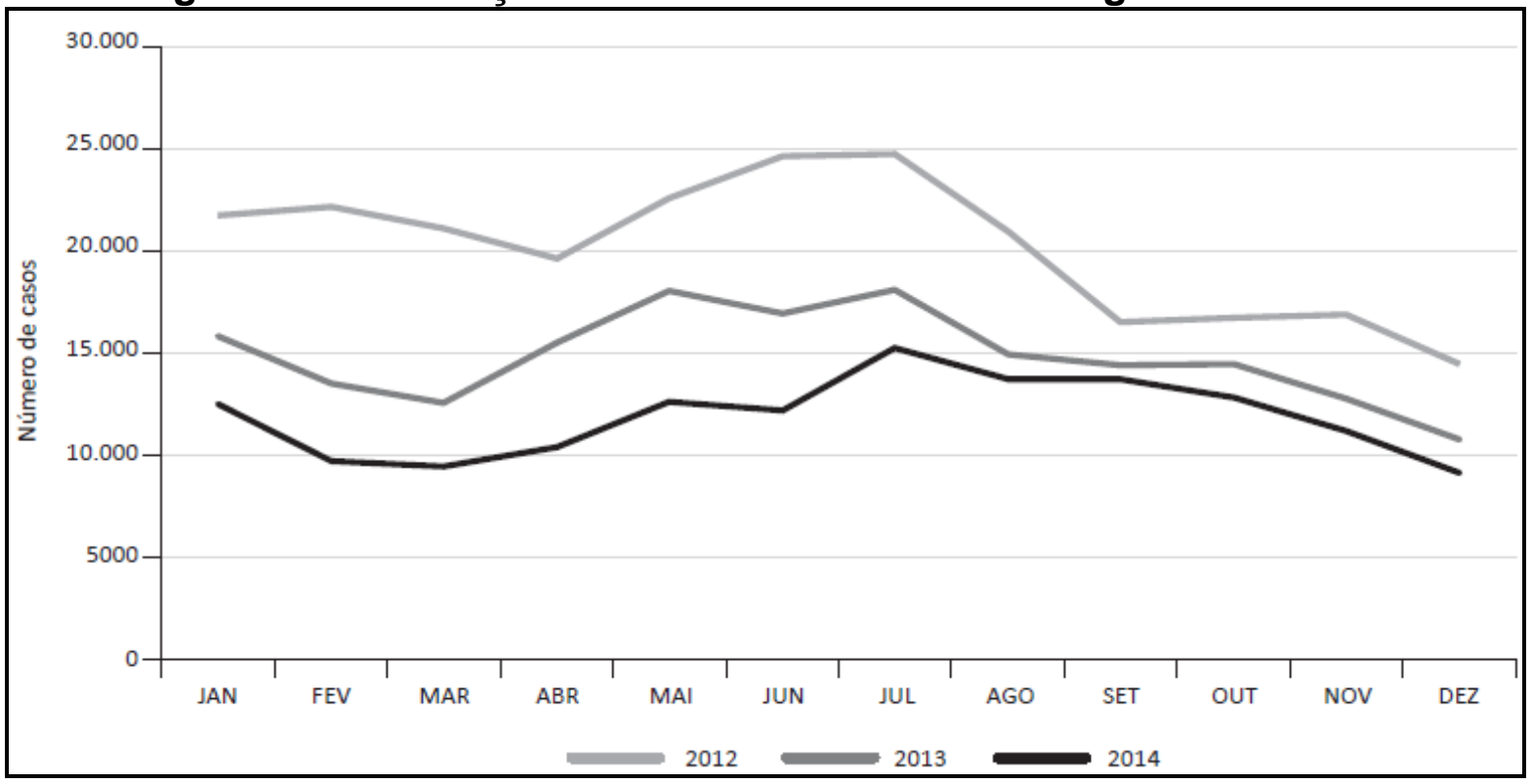

Casos de malária na Região Amazônica, entre os anos de 2012 a 2014 (modificado de Ministério da Saúde 2016)(18).

No Brasil, o Ministério da Saúde criou o índice de Incidência Parasitária Anual (IPA), que classifica as áreas de transmissão em alta ( $\geq 50)$, média (<50 e $\geq 10)$, e baixa endemicidade $(<10)$, conforme o número de casos por mil habitantes, como exemplificado no mapa (Fig. 3). Trata-se de um índice essencial para investigar as variações populacionais, geográficas e temporais na distribuição dos casos de malária, sendo importante para os processos de planejamento e controle da malária no Brasil, em face da expansão territorial pelo ser humano(18).

As condições ambientais como a periodicidade das chuvas e temperatura, associadas às características socioeconômicas e aos diferentes fatores antrópicos como a migração da população rural para o meio urbano e a intensa exploração da vegetação, elevam as chances de infecção por plasmódio e são responsáveis pelos níveis epidêmicos da doença na região $(17,19)$. 


\section{Figura 3 - Mapa de risco da malária por município de infecção no Brasil}

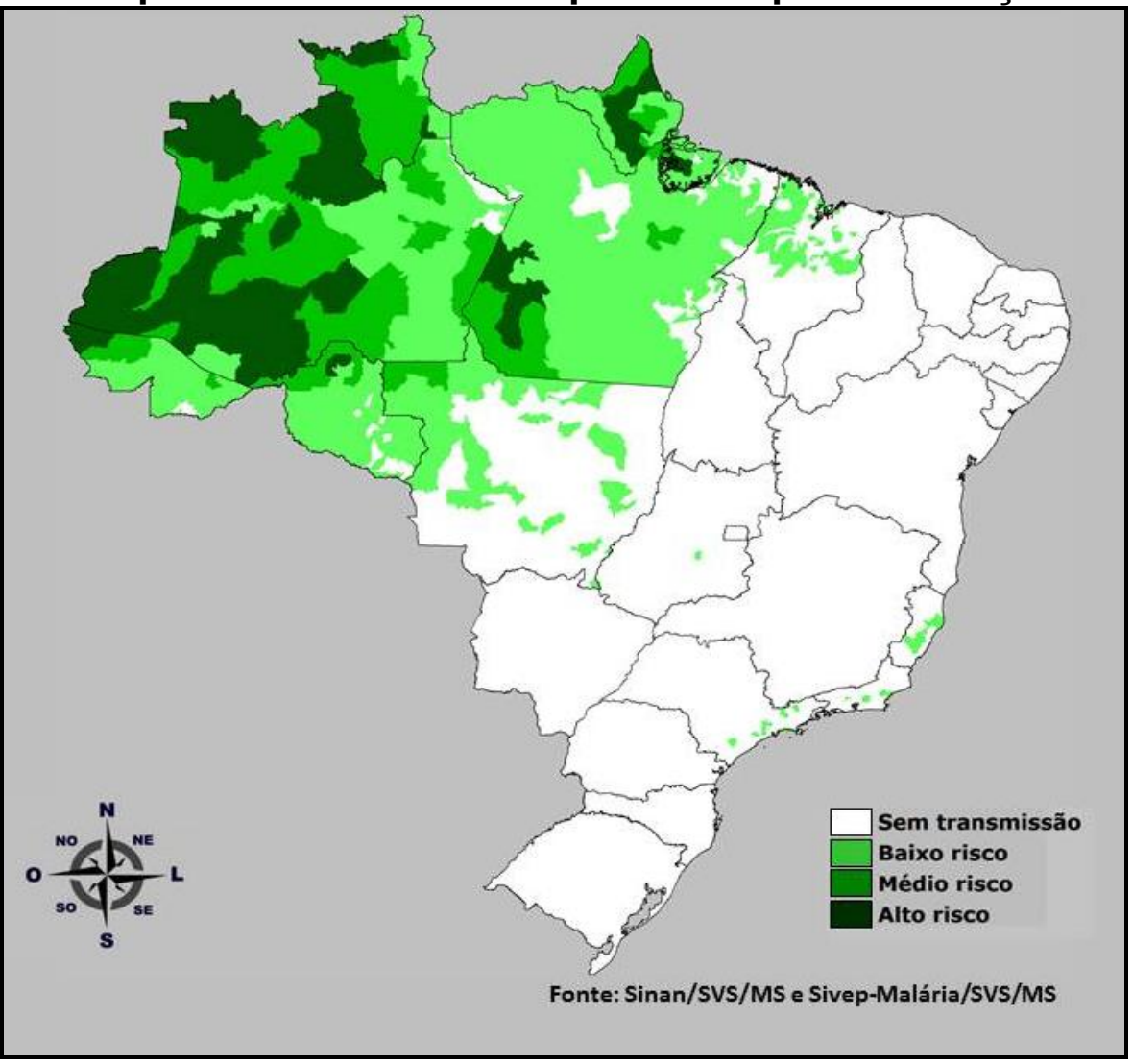

Distribuição das áreas com risco de transmissão de malária no Brasil com base na Incidência Parasitária Anual (IPA). Com destaque para a Região Amazônica com o maior risco de transmissão no país. (Modificado de Ministério da Saúde 2016).

\subsection{Ciclo de vida do parasito}

O Plasmodium spp. é um protozoário que possui um ciclo de vida complexo, envolvendo vetores invertebrados, os mosquitos da família Culicidae, e hospedeiros vertebrados. Os mosquitos são conhecidos por serem excelentes transmissores de doenças humanas, especialmente em regiões tropicais e subtropicais, onde as condições climáticas se mantêm constantes(20). No Brasil, o principal vetor da malária é o Anopheles darlingi, uma espécie antropofílica (por preferencialmente se alimentar de sangue humano) que possui periodicidade noturna, com picos crepusculares(21). Quando a fêmea do mosquito faz o repasto sanguíneo em um hospedeiro infectado com o plasmódio, basta apenas um gametócito feminino e um gametócito masculino viáveis e totalmente desenvolvidos para que o mosquito dê continuidade ao ciclo do parasito(20).

Os gametócitos alcançam o lúmen posterior do intestino médio da fêmea, único ambiente no organismo do mosquito para armazenamento, digestão e 
absorção do sangue. Neste ambiente termina a fase sexuada do ciclo: os gametócitos modificam-se rapidamente em microgametas extracelulares móveis (masculinos) e macrogametas fixos (femininos), fundem-se e ocorre a formação do zigoto. Após a meiose, o zigoto diferencia-se em uma forma de alta mobilidade deslizante, chamado de oocineto. A partir da ruptura da matriz peritrófica circundante (membrana da parede do intestino de insetos), os oocinetos são capazes de penetrar no epitélio do intestino médio do mosquito. Em seguida, esses oocinetos fixam-se sob a lâmina basal da face ectoperitrófica da parede do intestino, tornando possível sua transformação em oocistos (estágio esférico fixo). Estes oocistos passam por um processo de esporogonia, no qual múltiplas replicações mitóticas geram milhares de esporozoítos haploides, os quais são liberados com a ruptura do oocisto. Nesse estágio, os esporozoítos percorrem toda a cavidade corporal do mosquito através da hemolinfa, até alcançarem a lâmina basal, que rodeia as glândulas salivares, e atingirem as células acinares produtoras de saliva. Dessa forma, os esporozoítos acumulam-se nas cavidades salivares, sendo capazes de se locomoverem até os estreitos canais salivares que se conectam à tromba. Assim, os esporozoítos estão prontos para serem inoculados na derme do hospedeiro intermediário vertebrado, no próximo repasto sanguíneo do Anopheles spp. (Fig.4)(10,22-25).

Após inoculados, os esporozoítos podem migrar rapidamente entre as camadas da pele até atingir os capilares(24). Assim, os parasitas alcançam a corrente sanguínea e chegam até o fígado onde se diferenciam. Aqueles que não conseguem ter mobilidade suficiente e permanecem na pele são destruídos pela resposta imune inata do hospedeiro(26).

Após infectar os hepatócitos, os esporozoítos começam um período de reprodução assexuada (conhecido como esquizogonia tecidual ou merogonia intrahepática) e desenvolvem-se em esquizontes, contendo milhares de merozoítos. Os hepatócitos tumefeitos rompem-se e libertam os merozoítos para a corrente sanguínea. Diferente do que ocorre com $P$. falciparum, o $P$. vivax possui a particularidade de estacionar no estágio hepático sob a forma denominada de hipnozoíto e, nessa forma, pode permanecer em estado de latência, ou seja, retornar após semanas, meses ou até mesmo anos. Portanto, o hospedeiro pode voltar a ter a infecção mesmo após o tratamento, devido à reativação dos hipnozoítos(27). 
O estágio seguinte ao trofozoíto denomina-se esquizonte intra-eritrocítico, fase caracterizada pela multiplicação do parasita no interior da hemácia e pela intensa síntese de moléculas de extrema importância para a invasão de novos eritrócitos. Essa fase é seguida pelo surgimento de vários pontos de origem de formação de merozoítos. Com a hemoglobina do eritrócito tendo sido quase toda consumida pelo parasita ocorre o aumento do pigmento malárico (hemozoína), que em excesso pode ser prejudicial para o parasito. Após o desenvolvimento final dos novos merozoítos, a membrana do eritrócito e a membrana do vacúolo parasitóforo rompem-se, provavelmente por um processo dependente de proteases e, dessa maneira, os novos merozoítos estão prontos para infectar novos eritrócitos na corrente sanguínea(28,29).

$\mathrm{Na}$ fase eritrocítica, os merozoítos invadem as hemácias e replicam-se dentro destas. Esses ciclos de replicação são sincronizados nas espécies $P$. falciparum e $P$. vivax, durando aproximadamente 48 horas. É nesse estágio do ciclo biológico do parasito que surgem os sintomas da doença(27). Os principais sintomas são: sudorese, calafrios e febre, que pode passar dos $40^{\circ} \mathrm{C}$. Convém salientar que $\mathrm{O}$ estado febril do indivíduo está relacionado com o período de horas que o parasito leva para romper as hemácias parasitadas. 
Figura 4 - Ciclo de vida do Plasmodium spp. no hospedeiro vertebrado e no mosquito anofelino

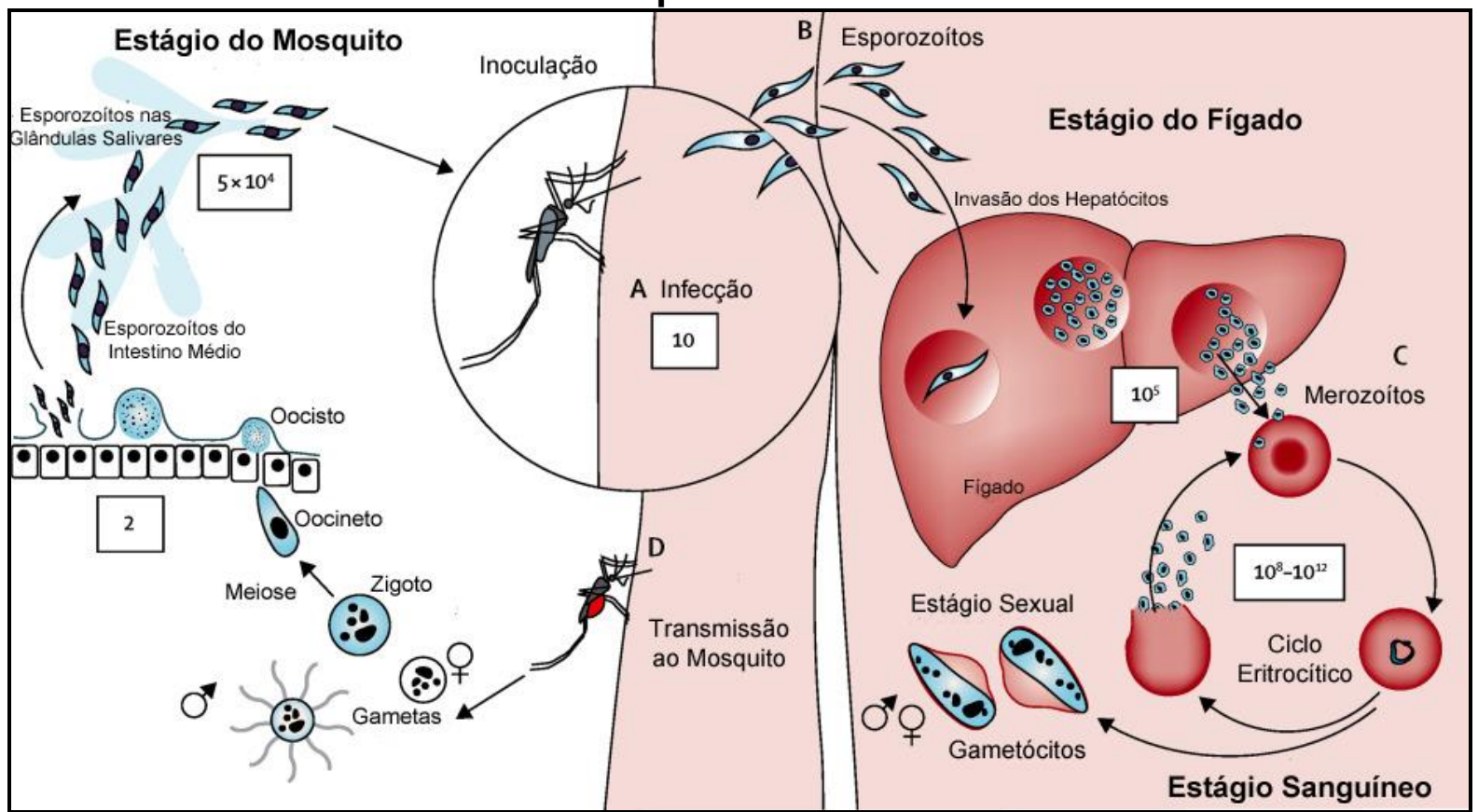

O ciclo de vida do Plasmodium spp. pode ser dividido em duas fases: a replicação assexuada no hospedeiro humano e sexuada no mosquito vetor. O ciclo se inicia com a inoculação de esporozoítos na pele do hospedeiro humano (A, amplificado). Esses esporozoítos entram na corrente sanguínea e circulam para o fígado, onde invadem ativamente os hepatócitos (B); dentro dos hepatócitos, cada esporozoíto replica-se assexuadamente. Após cerca de uma semana, os esquizontes do fígado rompem-se, liberando milhares de merozoítos na corrente sanguínea que vão invadir os eritrócitos e iniciar o ciclo eritrocítico (C). A doença desencadeia sua manifestação clínica quando o número total de parasitas assexuados na circulação atinge aproximadamente $10^{8}$. Alguns parasitas desenvolvemse em formas sexuais (gametócitos). No momento do repasto sanguíneo de um mosquito anofelino, os gametócitos são capturados (D), e reproduzem-se sexuadamente formando um zigoto que se diferencia em um oocineto móvel. Este atravessa a parede do intestino médio para depois formar um oocisto. O oocisto rompe-se e libera os esporozoítos, que migram para as glândulas salivares para aguardar a inoculação no próximo repasto sanguíneo. O ciclo completo deve demorar aproximadamente uma semana (Modificado de White NJ. et al., 2014)(11).

\subsection{Malária grave}

Como já citado, uma vez rompidos os eritrócitos infectados durante a fase assexuada do ciclo, há a liberação dos merozoítos e dos produtos de seu metabolismo na corrente sanguínea do hospedeiro, promovendo, assim, a ativação de uma cascata de mediadores inflamatórios, a qual é responsável por muitos sintomas típicos da malária, a saber: febre, calafrios, sudorese, dores nas articulações, dores de cabeça, mialgias, náuseas, vômito, tontura, dentre outros. Contudo, são sintomas da malária não complicada, a qual, muitas vezes, pode evoluir rapidamente para a forma grave da doença(30).

A malária grave é por definição a forma mais severa da doença, associada a um alto índice de mortalidade e clinicamente precedida pela malária assintomática 
e/ou pela forma não-complicada da doença(31). As principais complicações da malária grave incluem o comprometimento cerebral e pulmonar, lesões hepáticas e renais, anemia severa e/ou hemorragia, acidose metabólica, hipoglicemia, além da malária placentária. Em muitos pacientes estas complicações podem aparecer concomitantemente, e todas possuem potencial para se desenvolver de modo rápido, progredindo para a morte em dias ou horas $(32,33)$.

Um importante aspecto da patogênese da malária grave provocada por $P$. falciparum resulta da habilidade de eritrócitos parasitados (EP) serem sequestrados na microvasculatura do hospedeiro. Este envolvimento pode ser um resultado direto do bloqueio dos vasos sanguíneos ou efeitos causados pela interação entre os EP e o endotélio, o que inclui a resposta inflamatória local(34). Como consequência, a adesão promove o desaparecimento das formas assexuadas do parasito da circulação periférica, evitando, assim, que estes sejam destruídos no baço e favorecendo ainda mais a infecção(14,35,36).

\subsection{Malária durante a gravidez}

A malária é uma doença parasitária grave e potencialmente fatal, que acomete cerca de 200 milhões de pessoas por ano, colocando em risco cerca 40\% da população mundial. Estima-se que ocorra cerca de 1 milhão de óbitos decorrentes dessa enfermidade(15). Anualmente, quase 50 milhões de mulheres que vivem em zonas endêmicas tornam-se grávidas, aumentando o risco de sofrerem as complicações associadas às infecções por Plasmodium falciparum(37). Essa enfermidade é uma das principais causas de mortalidade em regiões tropicais, acarretando em cerca de 10.000 mortes maternas e entre 75.000 a 200.000 mortes infantis a cada ano(38). Além de ser uma importante causa de mortalidade maternoinfantil, a malária na gravidez (MIP, do inglês Malaria in Pregnancy) traz como consequência o aumento do número de abortos, de nascimentos prematuros, de anemia e de retardo nos desenvolvimentos fetal e infantil(39-41).

O motivo das mulheres grávidas serem particularmente suscetíveis às infecções por $P$. falciparum tem merecido intenso debate nos últimos anos. A princípio, foi proposto que seria devido à imunoregulação materna que, por um lado, protege o feto contra a ação do sistema imunológico, por outro, deixa-a menos resistente às infecções $(42,43)$. Entretanto, atualmente acredita-se que a placenta 
ofereça um ambiente único para o desenvolvimento de subpopulações de parasitos que se ligam a receptores como a Condroitina Sulfato A (CSA) presente em grande quantidade nesse órgão(44). Assim, os eritrócitos parasitados (EP) são sequestrados e multiplicam-se no ambiente placentário, evitando a sua posterior destruição pelo baço. Um intenso infiltrado inflamatório constituído predominantemente por macrófagos desenvolve-se no espaço intervilar da placenta e, por conseguinte, há a produção de citocinas pró-inflamatórias, associadas a abortos, restrição de crescimento intrauterino, partos prematuros e baixo peso ao nascimento(45).

Uma imunidade específica contra as formas placentárias do parasito é adquirida após sucessivas gestações, podendo prevenir o sequestro e, dessa maneira, evitar a cascata de eventos inflamatórios que conduzem ao agravamento da doença $(39,46)$. Paradoxalmente, mulheres que vivem em áreas de alta endemicidade muitas vezes apresentam poucos sintomas da doença. Em particular, os mais severos efeitos da malária são observados na primeira e na segunda gravidez, indicando a existência de um mecanismo de proteção associado à imunidade específica diante das formas placentárias do plasmódio, o que poderia ser reforçado pela vacinação(43). Nestas mulheres, o aumento dos níveis de parasitemia durante a gestação consiste em um indicador de suscetibilidade. Entretanto, as informações relacionadas aos mecanismos responsáveis pela recrudescência da infecção durante a gravidez são de difícil acesso nas populações humanas. Além disso, a malária pode ser assintomática durante a gravidez e, mesmo assim, trazer sérios prejuízos ao desenvolvimento fetal, sugerindo um complexo mecanismo de patogênese ligado à recrudescência, às lesões placentárias e, portanto, a restrição no desenvolvimento intrauterino(47).

\subsection{Malária placentária}

Histologicamente, placentas afetadas pela malária são caracterizadas pelo acúmulo de parasitos e leucócitos maternos (monócitos e neutrófilos) no espaço interviloso, presença de pigmentos de hemozoína no interior de macrófagos, depósito de fibrina, proliferação exacerbada das células citotrofoblásticas e espessamento da membrana basal que suporta a camada trofoblástica, diminuindo, assim, a eficiência das trocas entre mãe e feto nessas áreas(48-51). De fato, a 
restrição do crescimento intrauterino e o baixo peso ao nascer são resultados desse comprometimento da superfície de trocas entre mãe e feto, o qual culmina em hipóxia e inflamação(50,52).

A malária placentária é particularmente observada em infecções causadas pelo $P$. falciparum (maior números de casos no continente africano); todavia, trabalhos apontam para a importância do $P$. vivax (com maior ocorrência de casos na Ásia e América do Sul), apesar de esta ser considerada uma espécie com menor grau de severidade para gestantes, quando comparada com o $P$. falciparum(37,53$55)$.

Nas infecções provocadas pelo $P$. falciparum, o mecanismo pelo qual desenvolve-se a malária placentária já é conhecido. Nesse processo, a proteína PfEMP-1 liga-se ao glicosaminoglicano Condroitina Sulfato A (CSA) (Fig. 5). A particularidade desta ligação reside no fato de que este CSA placentário possui uma sequência de aminoácidos única, não encontrada em nenhum outro órgão do corpo. Na placenta este CSA compõe a estrutura do proteoglicano Syndecan-1, produzido de forma abundante pelo sinciciotrofoblasto. Uma vez que a conformação do Syndecan-1 expõe o CSA ao contato direto com o sangue que circula nas lacunas placentárias, o órgão torna-se um ambiente propício à ligação e ao sequestro dos eritrócitos parasitados(56). A consequência disso, como já abordado, é o escape da remoção dos parasitos pelo baço, propiciando a infecção e tornando as comorbidades associadas à malária gestacional mais severas(57).

A família de proteínas PfEMP-1 é codificada por ser uma das principais famílias de multigenes do $P$. falciparum, denominada de genes var. Essa família multigênica compreende mais de 60 genes já identificados, os quais são transcritos aleatoriamente. Embora muitos genes sejam transcritos no estágio de anel do parasito, somente um produto do gene vai ser expresso na superfície do eritrócito. A variabilidade genética pela qual milhões de novas estruturas antigênicas podem ser geradas em um único indivíduo infectado ajuda o parasito a escapar do reconhecimento imune e adaptar-se a novos ambientes do hospedeiro(58-60).

A PfEMP-1 é sintetizada pelo plasmódio e exportada do vacúolo parasitóforo até a superfície da membrana plasmática do eritrócito infectado. Esta proteína é constituída de vários domínios de ligação tipo Duffy (DBLs) e regiões entre os domínios ricos em cisteína (CIDRs), responsáveis pela adesão a diversos receptores celulares(61). Esses domínios são altamente polimórficos e podem ser classificados 
em classes e subclasses distintas(59). A região extracelular da VAR2CSA compõese de seis subdomínios DBL mais uma região interdomínios ricos em cisteína. A ligação ao CSA envolve resíduos básicos nos subdomínios 2 e 3 (subdomínios pertencentes ao domínio DBL) $(58,59,62)$ (Fig. 5).

A malária placentária resultado sequestro de eritrócitos infectados na placenta. Em virtude da presença destes, o sinciciotrofoblasto e as células monucleares maternas são estimulados a liberarem quimiocinas atrativas de monócitos e macrófagos, tais como CCL2/MCP-1, CCL3/MIP-1 $\alpha$, MIP-1 $\beta$ e IL-8(6366). Assim, instaura-se um intenso infiltrado inflamatório na placenta. Esse perfil inflamatório caracteriza-se principalmente pela presença de monócitos/macrófagos maternos, que são consideradas células efetoras diretas no ataque aos eritrócitos infectados(67). Uma vez ativadas, em decorrência da infecção placentária, essas células monucleares maternas e a ação do sinciciotrofoblasto são fortemente associadas ao aumento nos níveis de citocinas do perfil pró-inflamatório. Apesar dessa citocinas inflamatórias visarem a eliminação do parasito pelo aumento da atividade fagocítica de macrófagos, a produção exacerbada destas pode acarretar modificações da homeostase local, sendo capaz, inclusive, de gerar alterações morfológicas e fisiológicas do órgão(68).

$O$ aumento nos níveis normais de TNF- $\alpha$ (produzido principalmente por macrófagos) e IFN-y durante a gestação estão associados a resultados adversos no nascimento. Embora essas citocinas sejam fundamentais para a defesa do hospedeiro, sua produção exacerbada é correlacionada com o perda da capacidade placentária detransferir nutrientes para o feto(69). 


\section{Figura 5 - Ligação de eritrócitos parasitados na microvasculatura e nas vilosidades placentárias}

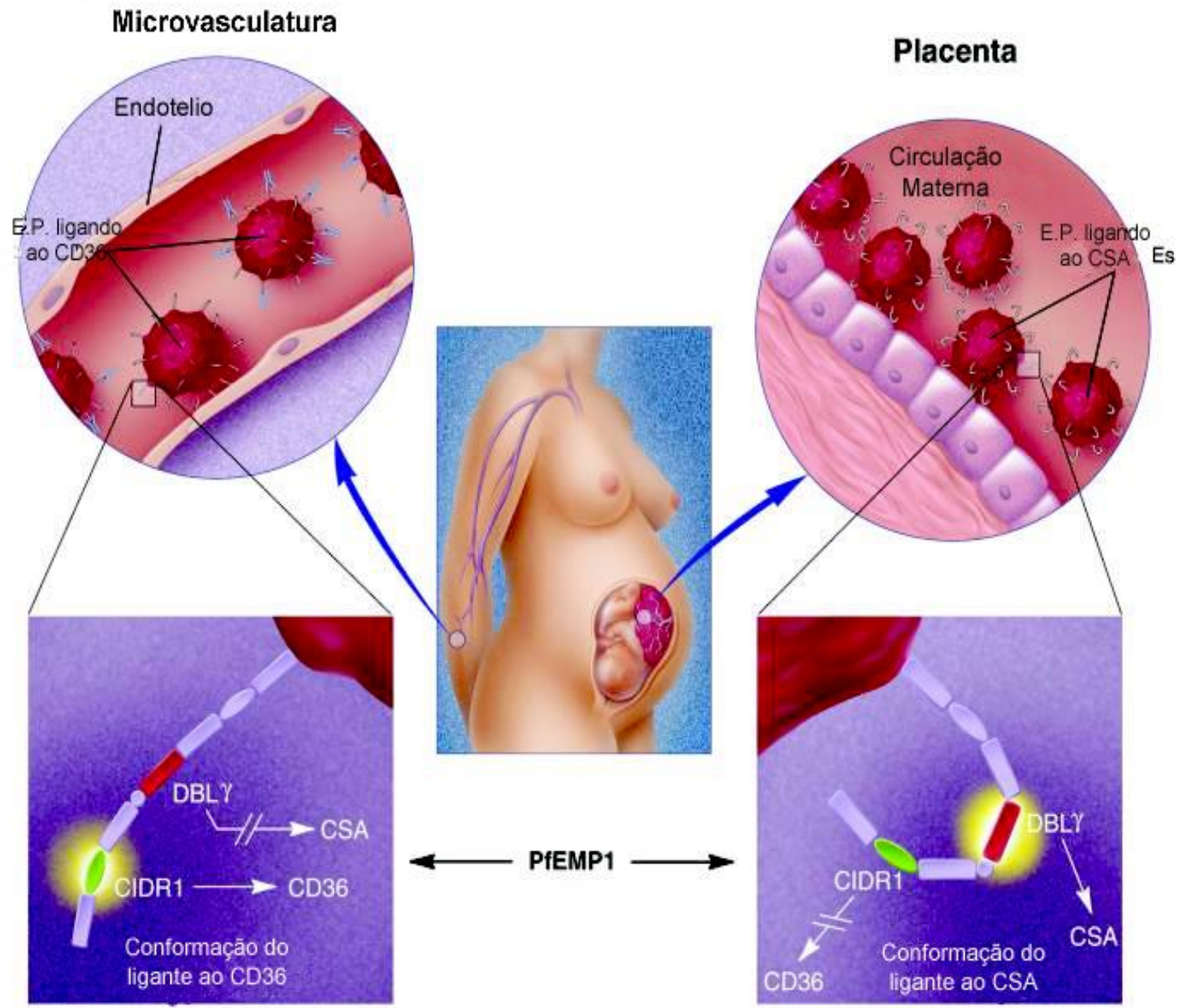

Mulheres no período gestacional, principalmente as primigrávidas, podem apresentar um sequestro de eritrócitos parasitados (EP) na placenta, por não serem reconhecidos pelos anticorpos existentes antes da gestação. Esses EP ligam-se ao CSA por meio da variante da PfEMP-1. As PfEMP-1 de parasitas aderentes ao CSA possuem uma conformação estrutural única, permitindo que o domínio DBLy (domínio y de ligação tipo Duffy) ligue-se ao CSA (quadro inferior direito), ao passo que, na microvasculatura, os EP se ligam ao CD36 vascular utilizando o domínio CIDR1 (interdomínio da região 1 rica em cisteína) da PfEMP-1 (quadro inferior esquerdo). (Modificado de Gamain B. et al., 2002)(70).

$\mathrm{Na}$ malária placentária as alterações da placenta estão atreladas às modificações histopatológicas, incluindo a degradação do sinciciotrofoblasto e subsequente destruição da integridade dos vilos da placenta, a necrose fibrinoide e o espessamento da membrana basal trofoblástica; consequentemente aumentando o risco de baixo peso ao nascer, em virtude da restrição do crescimento intrauterino e parto prematuro(69). 


\subsection{Placenta}

A placenta é um órgão transitório que se origina durante a gestação, exercendo a função de interface entre mãe e feto, indispensável para o sucesso da gravidez. A placenta executa uma infinidade de funções, dentre as quais destacamse 0 aporte nutricional, as trocas metabólicas e gasosas entre mãe e feto, a regulação endócrina e a ativação de mecanismos de tolerância imunológica. O estabelecimento do diálogo materno-embrionário se dá a partir da secreção de numerosas substâncias pela placenta, tais como hormônios, fatores de crescimento, citocinas, eicosanoides e outras moléculas bioativas sintetizadas. Além disso, a placenta atua na linha de defesa contra patógenos que podem alcançar este órgão.(71-74).

O processo de formação da placenta conta com a participação de populações celulares, tanto maternas quanto fetais. No caso da placenta hemocorial, presente em primatas e roedores, essa interação entre mãe e feto é tão íntima que o sangue materno banha diretamente as estruturas coriônicas, de origem fetal $(75,76)$.

A placentação é precedida pelo processo pré-implantacional, no qual o blastocisto invade o endométrio materno e se estabelece, de modo a possibilitar a formação de um sistema de trocas entre os organismos materno e embrionário(72). Nesta fase, o blastocisto forma-se pela massa celular interna e uma cavidade denominada blastocele, ambas revestidas pela trofoectoderme, da qual se originam as distintas populações de células trofoblásticas que formarão a porção fetal da placenta $(77,78)$.

Em camundongos por volta do $6^{\circ}$ e $7^{\circ}$ dias de prenhez, as células trofoblásticas situadas acima da massa celular interna do blastocisto proliferam de forma muito intensa, originando uma excrescência denominada cone ectoplacentário. Por sua vez, as células mais periféricas desta estrutura diferenciamse em células gigantes, as quais possuem um grande potencial invasivo e fagocítico, invadindo o tecido materno para formar a estrutura placentária. Já as células mais internas do cone ectoplacentário mantêm sua capacidade proliferativa e diferenciamse em células do espongiotrofoblasto, uma camada da placenta formada por células que acumulam glicogênio e por células endócrinas produtoras de hormônios como o lactogênio placentário. As células trofoblásticas da base dessa estrutura (também chamadas de ectoderma extraembrionário ou ectoderma coriônico) organizam-se 
junto com o mesoderma alantoideano para formarem as estruturas coriônicas do labirinto placentário, região responsável pelas trocas entre mãe e feto. Por fim, ao redor do $10^{\circ}$ dia de prenhez esse mesoderma torna-se vascularizado, configurando aí a formação de uma placenta completa, porém imatura, a qual se tornará amadurecida por volta do $14^{\circ}$ dia de prenhez(79-83) (Fig.6A).

Por meio desse processo há a estruturação de uma placenta hemocorial, a qual possui um formato discoide e é formada por três camadas distintas: a decídua (por onde chegam as artérias maternas), o espongiotrofoblasto e o labirinto(82) (Fig.6A). O objeto deste trabalho foi a camada do labirinto, região onde não só o sangue oriundo dos vasos maternos circula, como também os eritrócitos infectados por Plasmodium sp., assim como o parasita na sua forma livre. As estruturas coriônicas do labirinto são constituídas por uma camada trilaminar de células trofoblásticas que separam os capilares fetais do sangue materno circulante, a qual deriva da diferenciação do trofoblasto que reveste a estrutura coriônica inicial. Esta é composta mais internamente por uma bicamada sincicial ou de sinciciotrofoblasto envolvendo o endotélio dos vasos sanguíneos fetais e o mesênquima; e mais internamente por uma camada de células trofoblásticas gigantes (mononucleares) revestindo o espaço por onde o sangue materno circula (também chamados de sinusoides maternos(76,84-86) (Fig.6B). 
Figura 6 - Desenvolvimento da placenta murina

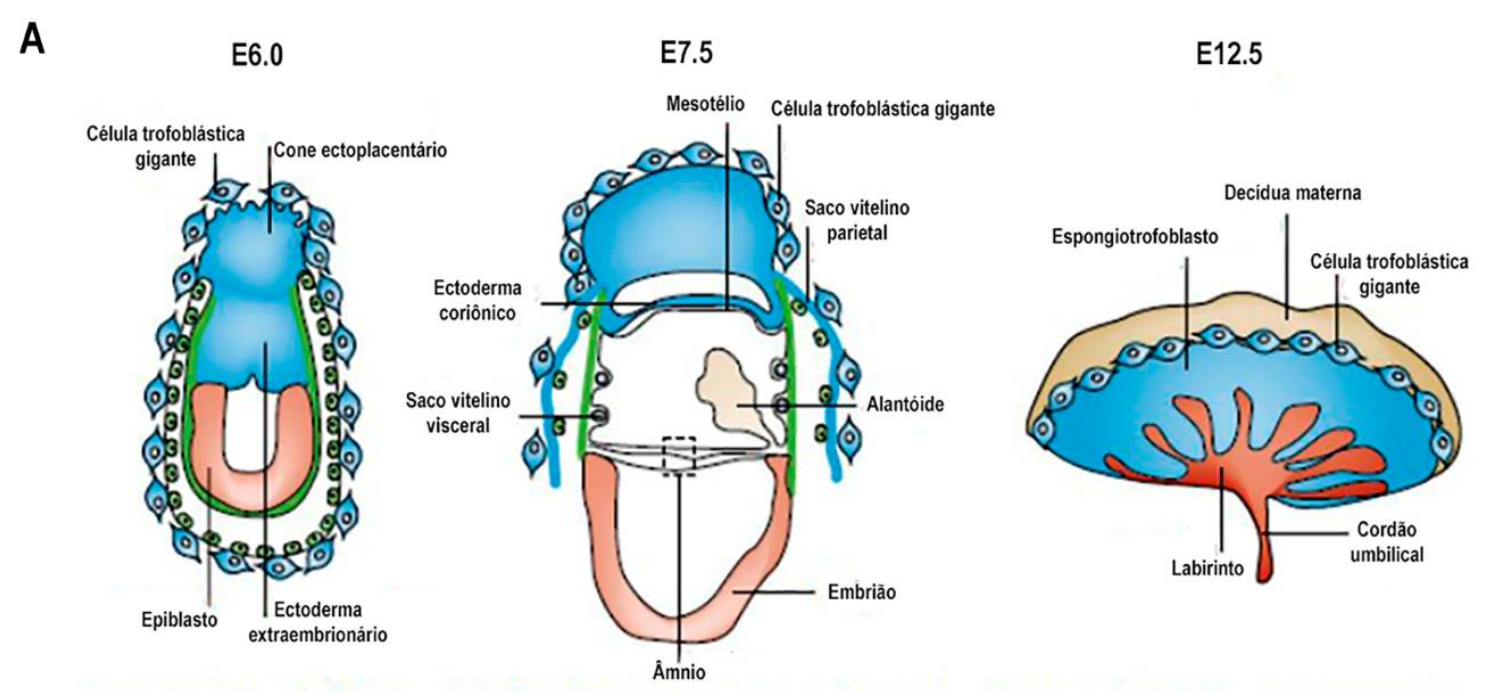

B

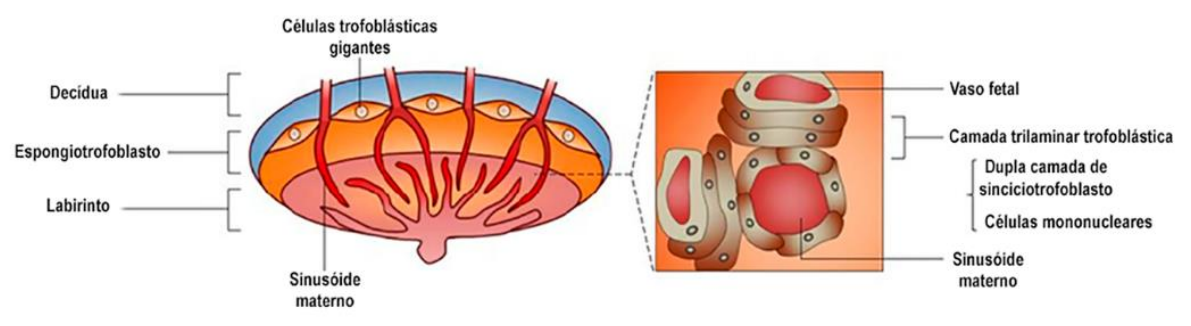

(A). Desenvolvimento do embrião de camundongo a partir do dia embrionário (E) 6 - E12.5. (Modificado de Rossant J, Cross JC, 2011)(82). (B). Estrutura da placenta de camundongo. (Modificado de Yamashita et al., 2011)(87).

Por sua vez, a vasculatura fetal na placenta, acomodada no interior das estruturas coriônicas do labirinto, conflui e liga-se ao feto em desenvolvimento por meio da veia e artérias umbilicais. Assim, os sinusoides com sangue materno permeiam as ramificações coriônicas do labirinto, banhando-as diretamente. Nesse processo, os sangues materno e fetal estabelecem um fluxo contracorrente dentro do labirinto para maximizar o transporte de nutrientes $(79,82,85,88)$. Perturbações nessa região, como as provocadas pela presença do Plasmodium berghei, podem afetar essas trocas entre a mãe e o feto.

Outro aspecto interessante refere-se à receptividade da mãe para o desenvolvimento placentário e do embrião/feto (que possuem padrões antigênicos geneticamente diferentes da mãe), e que tem sido relacionada à existência de uma modulação do sistema imune materno. Em condições normais na gestação, esses padrões antigênicos relacionados ao tecido placentário não sofrem a ação do sistema imunológico materno; assim, não geram respostas negativas no decorrer da prenhez. A intrínseca associação entre as células de origem fetal e materna vai 
garantir o sucesso gestacional. Neste sentido, a placenta também é uma barreira entre o sangue materno e o sangue fetal, protegendo o feto de um possível ataque do sistema imune. No entanto, a ocorrência de infecções durante a gestação, como no caso da malária gestacional, leva à disfunção desse delicado balanço imunológico, acarretando prejuízos para a mãe e o feto. Visto isso, os desfechos deletérios da malária durante a gestação podem ser consequência da somatória de efeitos associados às imunidades humoral e celular, e às alterações ocorridas durante o desenvolvimento da placenta, ocasionando a disfunção do órgão(64,89).

\subsection{Autofagia}

A autofagia é um processo catabólico fundamental para a homeostase celular, e é o único sistema para degradação de grandes componentes celulares que não podem ser destruídos pela via ubiquitina-proteassoma. Esse mecanismo está bem conservado entre os diversos grupos de organismos vivos, de leveduras até células eucarióticas superiores. Esse processo de "autodigestão" é responsável pela reciclagem de metabólitos, como macromoléculas solúveis e organelas, através da via lisossomal(90). A palavra autofagia foi criada pelo cientista Christian De Dove em 1963, e significa "autodigestão". Durante o processo autofágico, as proteínas celulares de longa duração e organelas danificadas e/ou envelhecidas são sequestradas por vacúolos de dupla membrana e destruídas nos lisossomos pela ação de hidrolases, a fim de manter a homeostase e integridade das células(91-93). O equilíbrio entre a síntese de proteínas e a degradação é de vital importância para o funcionamento e sobrevivência celular.

A autofagia é constitutivamente ativa em níveis basais nas células. A atividade autofágica é regulada principalmente pelo estresse metabólico celular, como, por exemplo: a falta de nutrientes, hipóxia, danos ao DNA, presença de patógenos e doenças inflamatórias. Diante disso, pode desempenhar o papel de um mecanismo de sobrevivência adaptativa. O mecanismo da autofagia pode permitir à célula o tempo necessário para estabilizar-se ante um ambiente estressor(91). Todavia, o contínuo estímulo do agente estressor pode contribuir para a morte celular, pois em células cancerosas a autofagia tem sido mostrada como um mecanismo de morte celular, o que poderia ser uma alternativa à via da apoptose $(94,95)$. 
Foram descritos diferentes tipos de autofagia: macroautofagia, microautofagia e a autofagia mediada por chaperonas. Na microautofagia, os componentes citosólicos a serem degradados são envoltos diretamente por uma invaginação da membrana lisossomal. Enquanto a autofagia mediada por chaperonas (observada apenas em mamíferos) é capaz de selecionar as proteínas citosólicas que devem ser degradadas. As proteínas contendo o motivo KERFQ de aminoácidos são reconhecidas pela chaperona Hsc70 e conduzidas ao lisossomo, onde podem passar através da proteína 2 associada à membrana do lisossomo (LAMP-2A), culminando na degradação. Por sua vez, a macroautofagia (denominada somente de autofagia) é a via principal, que vai englobar os conteúdos citoplasmáticos no interior de uma estrutura vesicular, denominada fagóforo; este pode ser originado da membrana citoplasmática do retículo endoplasmático ou da membrana mitocondrial externa. A fusão das extremidades do fagóforo formará uma estrutura de dupla membrana, denominada autofagossoma, a qual será combinada ao lisossomo, originando o autolisossoma. Logo, os três processos citados compreendem maquinarias moleculares bem semelhantes, resultando na decomposição e reciclagem dos seus conteúdos englobados no interior dos lisossomos $(93,96,97)$.

Os mecanismos moleculares da autofagia foram inicialmente descritos em leveduras, compreendendo mais de trinta genes (conhecidos como os genes da família Atg), os quais estão bem conservados em eucariotos superiores. Trata-se de um processo altamente dinâmico, onde ocorrem vários eventos envolvendo o tráfico de membrana.

A via da autofagia consiste em quatro eventos principais: iniciação/indução, elongação, maturação e fusão com o lisossomo. A proteína serina/treonina quinase mTORC1 (alvo de rapamicina em mamíferos) é um inibidor da indução autofágica, por fosforilar e inibir diretamente o complexo ULK1 (Atg13-ULK-FIP200-Atg101). A atividade de mTORC1 é estimulada dependendo de uma variedade de fatores que podem incluir não apenas a energia e nutrientes, como também a presença de aminoácidos e fatores de crescimento para as funções celulares. No entanto, a mTORC1 pode ser inibida pela falta de nutrientes para a célula. Desse modo, 0 ULK1 é diretamente fosforilado pela proteína quinase ativada AMP (AMPK) em resposta à restrição de nutrientes para a célula $(96,98)$.

A ativação do complexo ULK1 marca o início da autofagia e pode promover a sobrevivência celular(96). Concomitantemente, ocorre o início da nucleação da 
estrutura pré-autofagossomal ou local de formação do fagóforo (PAS), pela ação das proteínas Atg. A proteína PI3K de classe III (fosfatidilinositol 3-quinase de classe III) está envolvida nessa fase inicial, juntamente com Vps34, Beclin-1, Atg14L, entre outras. Essas proteínas em conjunto formam o complexo I Vps34, que deriva na nucleação do fagóforo. Esse complexo torna-se o principal ponto de regulação para as quinases que modulam a ativação da autofagia. Apesar de Beclin-1 ser reconhecida como uma proteína relacionada à autofagia e ser importante nesse complexo, ela mantém a associação com outras proteínas, como, por exemplo, Bcl-2 (uma proteína antiapoptótica). A fosforilação de Beclin-1 por DAPK (proteína quinase associada à morte) ou a fosforilação de Bcl-2 pela JNK (do inglês, $c$-Jun N-terminal kinase) desencadeia a dissociação do complexo Beclin-1/Bcl-2 em respostas a vários estímulos, permitindo que Beclin-1 associe-se ao complexo multiprotéico Vps34 para manter a sua função na via autofágica(99,100). A partir desse momento, ocorre o reconhecimento de conteúdos a serem englobados e segue a fase de alongamento e formação do autofagossoma(96,101) (Fig.7).

A continuação da expansão da membrana autofágica depende da interação inicial de dois sistemas de conjugação tipo ubiquitina: o sistema de conjugação Atg12 e o sistema de conjugação LC3(102). Atg12 é inicialmente expresso com uma glicina C-terminal, que será clivada pelo Atg7 (enzima tipo E1). O Atg12 é transferido para Atg10 (enzima tipo E2) e, finalmente, conjugado a um resíduo de lisina de Atg5(103). Por seguinte, a proteína LC3 ou MAP-1LC3 (proteína associada ao microtúbulo 1 de cadeia leve 3) também é formada com uma extensão do seu Cterminal, que será processada pela Atg4 (protease de cisteína) para expor sua glicina residual (a forma denominada de LC3-I)(104). Posteriormente, LC3-I ativada por Atg7, transferida para Atg3 (enzima tipo E2) e, por fim, mediante a ação do sistema de conjugação Atg12/Atg5, que funciona como uma enzima tipo E3, o LC3-I é ligada ao grupo amino de fosfatidiletanolamina (PE) (denominado de LC3-II ou LC3-PE)(105). A quantificação de LC3-II é frequentemente utilizada para estimar a abundância de autofagossomas no citoplasma celular. O complexo Atg12/Atg5 forma um novo complexo com Atg16, que torna possível selecionar o local de lipidação de LC3(106). Esse novo complexo (Atg12/Atg5/Atg16) é encontrado na membrana externa do autofagossoma e apenas se dissocia deste antes da formação completa do autofagossoma(107-110) (Fig.7). 
Embora a autofagia já tenha sido considerada como um processo aleatório de degradação de conteúdos citoplasmáticos, essa concepção mudou em face da descoberta de proteínas receptoras que sequestram diversos conteúdos, como mitocôndrias (mitofagia), agregados proteicos, ribossomos, entres outros. O LC3-II tem sido mostrado atuando como um receptor do fagóforo para essas proteínas adaptadoras e/ou carreadoras, visando uma absorção e degradação lisossomal seletiva(111). São conhecidas quatro proteínas adaptadoras capazes de reconhecer conteúdos citoplasmáticos ubiquitinizados: p62/SQSTM1, NBR1, optineurina e NDP52(112). A p62 foi a primeira proteína carreadora mostrada a mediar a ligação de proteínas ubiquitinizadas e entregá-las ao fagóforo para a degradação(113). Apesar de estar bem consolidado que autofagossomas formados pela autofagia seletiva não apresentam ou quase não contêm massa citoplasmática aleatória, não está claro o grau de seletividade da autofagia induzida pela falta de aminoácidos(109).

$\mathrm{Na}$ fase de maturação e/ou fusão, os autofagossomas formados aleatoriamente no citosol, movimentam-se direcionados por microtúbulos, para fundirem-se com os lisossomos. Após a fusão do autofagossoma com o lisossomo, esse vacúolo passa a ser denominado, conforme mencionado, de autolisossoma ou autofagolisossoma. Em células de mamíferos, a fusão é mediada pelas proteínas da membrana lisossomal LAMP-1 e LAMP-2, e pela pequena proteína G Rab7 quando ligada ao GTP. Contudo, esse mecanismo ainda é pouco caracterizado. Posterior à fusão, o processo de degradação da vesícula inicial ocorre pela ação das hidrolases lisossomais presentes no interior dos lisossomos para a degradação de componentes mediada por ATPases, fosfatases, lipases e, especialmente, proteases tais como: as catepsinas, calpaínas, caspases e presinilinas. O resultado do processo de degradação são principalmente aminoácidos, os quais são liberados no citosol pela ação das permeases presentes na membrana do lisossomo, para serem reciclados e participarem de síntese proteica e da manutenção das funções celulares em condições de privação de nutrientes $(91,114)$. Portanto, a autofagia pode estar envolvida em diversos processos de tentativa de recuperação da homeostase celular. 
Figura 7 - Representação esquemática da via autofágica

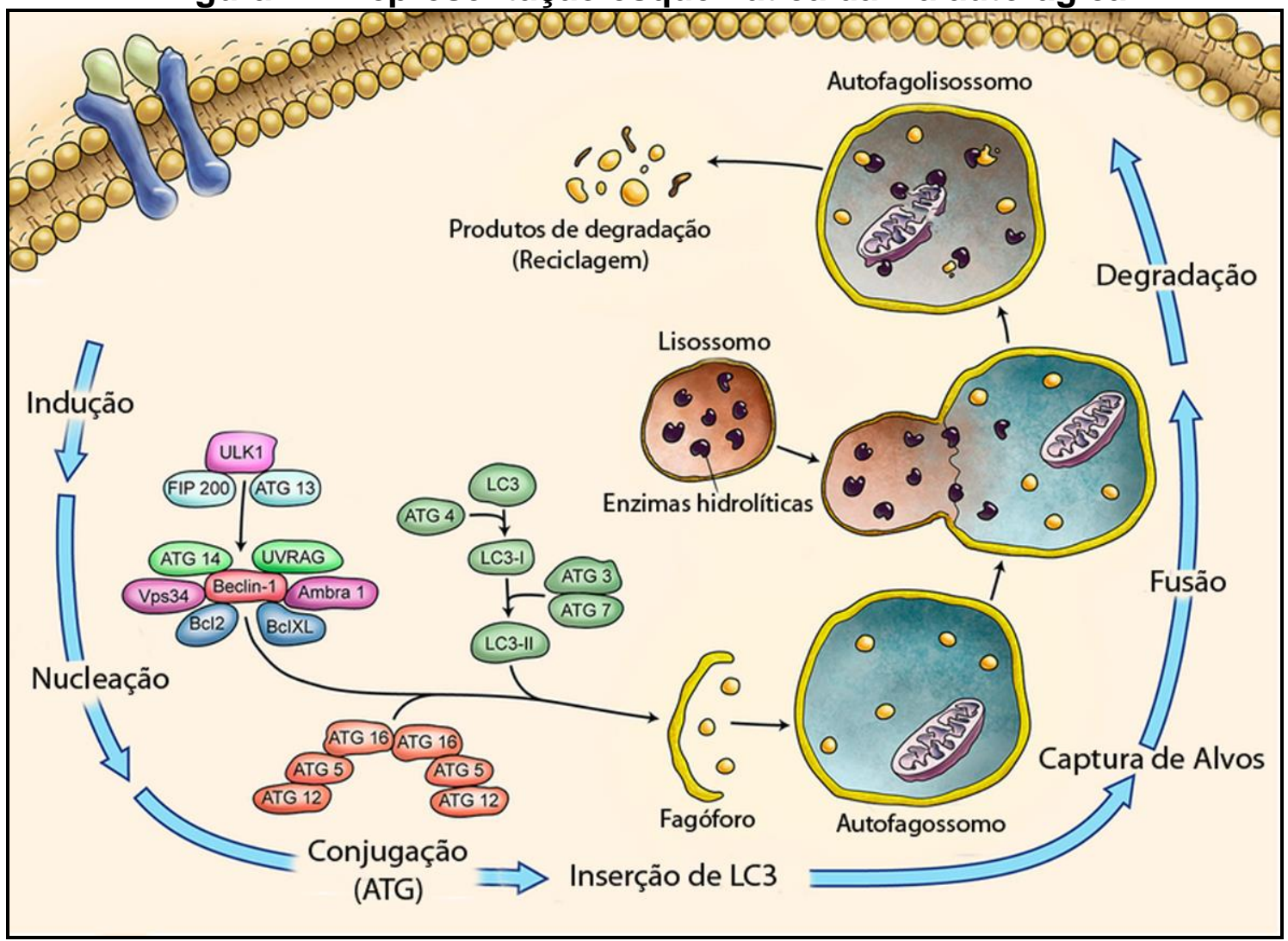

O processo autofágico envolve circuitos moleculares que iniciam com a nucleação (formação do fagóforo), seguida da conjugação de ATG5-ATG12 e da interação com ATG16L na estrutura formada; sequencialmente, há o processamento e a inserção de LC3 lipidado na membrana do fagóforo, agora denominado "autofagossomo". É nesta estrutura que ocorre a captura randômica ou seletiva de alvos para degradação. Posteriormente, o autofagossomo funde-se com o lisossomo, originando o "autofagolisossomo", no interior do qual as enzimas proteolítcas provenientes do lisossomo degradarão os alvos englobados. Por fim, há a liberação para o citoplasma dos produtos dessa degradação, os quais poderão ser reciclados pelas células. (Modificado de Marzban et al., 2015)(115).

\subsection{Autofagia no desenvolvimento}

Em todas as etapas de vida do mamífero, seja na formação e desenvolvimento do embrião, seja na fase de neonato e pós-nascimento, a autofagia exerce um papel primordial, possivelmente, devido à escassez de nutrientes e à alta demanda pela troca de proteínas e organelas durante o processo de remodelamento dos estágios iniciais da formação. A autofagia tem servido como hipótese por ser essencial na remoção de componentes dispensáveis do esperma e constituintes desnecessários do oócito(116). Além de ser necessária no remodelamento celular durante a diferenciação de eritrócitos, linfócitos e adipócitos; e de inequívoca relevância em células que vão ser diferenciadas, como neurônios e hepatócitos, nos quais a manutenção contínua da massa citoplasmática revela-se essencial $(90,117)$. 
A autofagia está presente no trofoblasto extraviloso, sendo importante no início da gestação para promover a invasão trofoblástica e remodelamento vascular uterino(118). A placenta humana é formada sob condições de hipóxia e privação de nutrientes. Já é conhecido que sob esses estressores, a via autofágica é ativada para atuar como um mecanismo protetivo, auxiliando a adaptação placentária. Logo, deficiências na autofagia durante esse estágio podem comprometer etapas cruciais da placentação, como a invasão e o remodelamento vascular(119-121).

Em camundongos, a autofagia é ativada poucas horas após a fecundação e é necessária para o seguimento de pré-implantação de embriões murinos, pois sua inibição suscita à morte embrionária no início da fertilização(122). A via da autofagia atua, presumivelmente, degradando proteínas maternas, permitindo, assim, que novas proteínas oriundas do zigoto sejam sintetizadas(123). Camundongos knockout para Atgs 3, 5, 7, 9 ou 16L não sobrevivem após o nascimento, devido ao decréscimo de aminoácidos no organismo. Após o nascimento, quando a nutrição não é mais feita através da placenta, ocorre um severo estresse nutricional induzindo o processo autofágico. A autofagia mostra-se importante em diversos órgãos como o cérebro, onde previne a formação de agregados proteicos e o acúmulo de organelas danificadas, o que poderia desembocar em doenças neurodegenerativas $(90,124)$.

Conforme tem sido mostrado, a autofagia está reduzida em placentas provenientes de trabalho de parto normal quando comparada a partos por cesárea eletiva(125). Um estudo recente demonstrou não haver diferença na expressão de proteínas autofágicas entre as placentas entregues por meio do trabalho de parto espontâneo e do parto induzido farmacologicamente(126). Segundo Brickle e colaboradores, proteínas da maquinaria autofágica (Beclin-1, Atg3, Atg5, Atg7, Atg12 e Atg16L1) estão reduzidas nas membranas fetais humanas, provenientes de trabalhos de parto espontâneo, prematuro e ruptura prematura das membranas. Além disso, esses autores demonstraram que a autofagia pode estar relacionada com o controle da inflamação induzida por infecção durante a gestação, induzindo o trabalho de parto prematuro(127). 


\subsection{Autofagia e inflamação}

As funções da autofagia abrange também o sistema imunológico(128). A via da autofagia e as proteínas autofágicas participam no controle da imunidade em organismos multicelulares, tais como o controle da resposta inflamatória como parte da imunidade inata(129), a apresentação de antígeno como parte da imunidade adaptativa e a função imunológica das células $\mathrm{T}$ e B(128,130).

Durante a infecção por algum patógeno invasor como bactérias, vírus e protozoários, a autofagia atua na resposta imune para degradar esses microrganismos dentro da célula, um processo denominado de xenofagia (um tipo de autofagia seletiva). Esse processo pode ter evoluído como um dos primeiros mecanismos de defesa autônomos em eucariontes. Semelhante à autofagia não seletiva (sequestro de massa citoplasmática aleatória), na xenofagia também é necessária a formação de um autofagossoma de dupla membrana que é fundido ao lisossomo para a destruição da carga. Apesar das duas formas serem semelhantes na utilização da maquinaria autofágica, a xenofagia depende de proteínas adaptadoras, por exemplo, a p62/SQSTM1 que se ligam aos patógenos invasores para entrarem em contato com a maquinaria autofágica e serem englobados para a degradação(131).

O processo inflamatório compreende um mecanismo importante empregado pelo sistema imunológico para a defesa do hospedeiro. Esse mecanismo de defesa depende de receptores, como os TLR para identificar padrões moleculares de patógenos e responder pela produção de citocinas pró-inflamatórias. Já foi demonstrado que TLR4 de macrófagos murinos são capazes de induzir a autofagia, após o estímulo com lipopolisacarideo (LPS)(132). Da mesma forma, o estímulo de TLR4 por LPS aumentou a degradação de Mycobacterium tuberculosis pela autofagia(133). Contudo, essa resposta pró-inflamatória deve ser bem controlada, pois a sua subativação ou hiperativação vai desencadear efeitos deletérios no hospedeiro(130,134,135). Presume-se que a autofagia pode regular uma resposta inflamatória extensiva, auxiliando na eliminação do complexo multiprotéico do inflamassoma, responsável pela produção e mobilização de citocinas. Relatórios científicos mostraram que defeitos na via autofágica contribuem para um aumento da resposta inflamatória, causado pela maior produção de citocinas pró-inflamatórias. 
Já foi demonstrado que o inflamassoma NLRP3 induz a produção das citocinas IL$1 \beta$ e IL-18 e que, na ausência de autofagia, estão aumentadas as produções dessas citocinas, levando à inflamação excessiva. Por outro lado, a ativação da autofagia sob essas condições pode eliminar componentes do inflamassoma NLRP3 e reduzir a resposta inflamatória exacerbada(136-139). Em face disso, constata-se que a autofagia tem relevância na função imunológica, o que a torna num alvo interessante para o desenvolvimento de novas terapias.

Vários grupos têm estudado as consequências da forma grave da malária, como, por exemplo, a malária durante a gravidez(140-142). Todavia, os mecanismos moleculares que, consequentemente, conduzem aos resultados negativos no final da gestação permanecem por ser elucidados. Uma possível explicação para a falta de conhecimentos a respeito da malária placentária é que os estudos abrangendo seres humanos são insatisfatórios, devido às limitações óbvias intrínsecas aos sistemas experimentais humanos e à acessibilidade ao material biológico nos diferentes estágios da gestação.

Uma vez que a placenta de camundongo possui muitas similaridades com a placenta humana, isso a torna um bom modelo, pois permite a manipulação genética e funcional. Dessa forma, os modelos murinos apresentam a possibilidade de estudos dos mecanismos imunopatológicos relacionados à malária placentária, em condições experimentais e controladas(82). O modelo experimental murino de infecção pelo plasmódio vem sendo utilizado pelo grupo desta pesquisa não apenas no estudo das populações e de mediadores imunológicos associados à malária durante a gravidez, assim como na análise dos fatores que propiciam 0 estabelecimento das lesões placentárias(49,143-145).

Tendo em vista que o perfil inflamatório é um fator crítico para o estabelecimento da malária placentária e conhecendo a importância da autofagia para a resposta imunológica; alterações no perfil autofágico devido a uma possível associação deste processo com a inflamação desencadeada, poderiam colaborar para o estabelecimento da patologia. Neste viés, estudos básicos voltados para a avaliação da regulação da autofagia em modelos animais de malária placentária poderão gerar novos conhecimentos sobre as disfunções celulares associadas à exposição ao Plasmodium spp. Estes conhecimentos, além de elucidar possíveis mecanismos envolvidos nos desfechos negativos da malária gestacional, poderão 
conduzir a estudos aplicados que visem o desenvolvimento de intervenções terapêuticas que se contraponham a estes. 
5. CONCLUSÃO 
Nossos dados demonstraram que a infecção pelo Plasmodium berghei NK65GFP em camundongos C57BL/6 induziu a ocorrência de partos prematuros, baixo peso fetal, da perda da correlação peso fetal/peso placentário e a alteração estrutural da placenta - com diminuição do espongiotrofoblasto, e espessamento do labirinto e da membrana interhemal. Ainda, essa modulação estrutural placentária parece estender-se também para o metabolismo do órgão, com a drástica diminuição do transportador Slc16A3 (MCT4) e indução da autofagia.

Em conjunto, esses dados servem para levantar a hipótese de que o baixo peso associado à infecção provavelmente reflete uma série de fatores ligados a adaptações estruturais e metabólicas da placenta, seguidas da insuficiência placentária. Em relação à autofagia nesse processo, o quanto sua ativação está diretamente envolvida é um ponto que permanece não claro, e que continuaremos investigando, através de inibidores e indutores da via e outros marcadores do fluxo autofágico; além de animais knockout para proteínas da autofagia.

Finalmente, a alta taxa de prematuridade e o dano tecidual observados no grupo infectado, com aumento nos níveis sistêmico e local de citocinas próinflamatórias, nos leva a crer que a inflamação pode ter um papel crucial na gênese das alterações e da insuficiência placentárias observadas. Assim, acreditamos que controlar a inflamação poderia ser uma das formas de amenizar as adaptações placentárias induzidas pelo parasita, atenuando os desfechos negativos observados na prole.

Nesse sentido, pesquisas relacionadas aos mecanismos envolvidos na adaptação placentária em resposta ao processo inflamatório parecem ser promissoras na busca de estratégias terapêuticas para a malária gestacional. 


\section{REFERÊNCIAS}




\section{REFERÊNCIAS 1}

1. Centers for Disease Control and Prevention. Malaria [Internet]. 2016 [cited 2016 Aug 15]. Available from: http://www.cdc.gov/malaria/

2. Cox FEG. History of human parasitic diseases. Infect Dis Clin North Am [Internet]. 2004 Jun;18(2):171-88, table of contents. Available from: http://www.ncbi.nlm.nih.gov/pubmed/15145374

3. MANSON-BAHR P. The malaria story. Proc R Soc Med [Internet]. 1961 Feb;54:91-100. Available from: http://www.ncbi.nlm.nih.gov/pubmed/21661463

4. Arrow KJ, Panosian C, Gelband H. Saving Lives, Buying Time: Economics of Malaria Drugs in an Age of Resistance [Internet]. Drugs. 2004. 388 p. Available from: http://www.nap.edu/catalog/11017.html

5. Gopalakrishnan AM, Kumar N, Orleans N. Encyclopedia of Malaria [Internet]. Kremsner PG, Krishna S, editors. New York, NY: Springer New York; 2016. 1-8 p. Available from: http://link.springer.com/10.1007/978-1-4614-8757-9

6. Cox FEG. History of human parasitology. Clin Microbiol Rev [Internet]. 2002 Oct;15(4):595-612. Available

from:

http://www.ncbi.nlm.nih.gov/pubmed/12364371

7. Meshnick SR, Dobson MJ. The History of Antimalarial Drugs. Antimalar Chemother Mech Action, Resist New Dir Drug Discov. 2001;15-25.

8. Talisuna AO, Bloland P, D'Alessandro U. History, dynamics, and public health importance of malaria parasite resistance. ClinMicrobiolRev [Internet]. 2004;17(0893-8512 (Print)):235-54. Available from: doi: 10.1128/CMR.17.1.235

9. Neafsey DE, Juraska M, Bedford T, Benkeser D, Valim C, Griggs A, et al. Genetic Diversity and Protective Efficacy of the RTS,S/AS01 Malaria Vaccine. N Engl J Med [Internet]. 2015;373(21):2025-37. Available from: http://www.nejm.org/doi/abs/10.1056/NEJMoa1505819\%5Cnhttp://www.ncbi.nl m.nih.gov/pubmed/26488565

10. de Koning-Ward TF, Dixon MWA, Tilley L, Gilson PR. Plasmodium species: master renovators of their host cells. Nat Rev Microbiol [Internet]. 2016 Aug;14(8):494-507. Available from: http://www.nature.com/doifinder/10.1038/nrmicro.2016.79

11. White NJ, Pukrittayakamee S, Hien TT, Faiz MA, Mokuolu OA, Dondorp AM. Malaria. Lancet [Internet]. 2014 Feb;383(9918):723-35. Available from: http://linkinghub.elsevier.com/retrieve/pii/S0140673613600240

12. Cotter C, Sturrock HJ, Hsiang MS, Liu J, Phillips AA, Hwang J, et al. The

1 De acordo com:

Internatonal Commitee of Medical Journal Editors. [Internet].Uniform requirements for manuscripts submited to biomedical journals. [2011 Jul 15]. Available from: htp://www.nlm.nih.gov/bsd/uniform_requirements.html. 
changing epidemiology of malaria elimination: new strategies for new challenges. Lancet [Internet]. 2013 Sep;382(9895):900-11. Available from: http://dx.doi.org/10.1016/S0140-6736(13)60310-4

13. World Health Organization. Guidelines for the Treatment of Malaria. Third Edition [Internet]. Third. 2015. 313 p. Available from: https://books.google.com.br/books?id=IVo0DgAAQBAJ

14. Greenwood BM, Fidock DA, Kyle DE, Kappe SHI, Alonso PL, Collins FH, et al. Malaria: progress, perils, and prospects for eradication. J Clin Invest [Internet]. 2008 Apr;118(4):1266-76. Available from: http://www.ncbi.nlm.nih.gov/pubmed/18382739

15. World Health Organization. World Malaria Report 2017 [Internet]. 2017 [cited 2018 Jun 2]. p. 196. Available from: http://www.who.int/malaria/publications/world-malaria-report-2017/en/

16. Unicef. Malaria mortality among children under five is concentrated in subSaharan Africa [Internet]. 2016 [cited 2016 Oct 25]. Available from: http://data.unicef.org/topic/child-health/malaria/

17. de Oliveira EC, dos Santos ES, Zeilhofer P, Souza-Santos R, Atanaka-Santos $M$. Geographic information systems and logistic regression for high-resolution malaria risk mapping in a rural settlement of the southern Brazilian Amazon. Malar J [Internet]. 2013 Nov 15;12:420. Available from: http://www.pubmedcentral. nih.gov/articlerender.fcgi?artid=3842636\&tool=pmce ntrez\&rendertype=abstract

18. Ministério da Saúde. Malária [Internet]. 2015. 2016 [cited 2016 Nov 19]. Available from: http://portalsaude.saude.gov.br/index.php?option=com_content\&view=article\&i $\mathrm{d}=10933 \&$ Itemid $=646$

19. Sampaio VS, Siqueira AM, Alecrim M das GC, Mourão MPG, Marchesini PB, Albuquerque $\mathrm{BC}$, et al. Malaria in the state of amazonas: A typical brazilian tropical disease infl uenced by waves of economic development. Rev Soc Bras Med Trop. 2015;48(Suppl I):4-11.

20. Rossati A, Bargiacchi O, Kroumova V, Zaramella M, Caputo A, Garavelli PL. Climate, environment and transmission of malaria. Infez Med [Internet]. 2016 Jun 1;24(2):93-104.

Available

from:

http://www.ncbi.nlm.nih.gov/pubmed/27367318

21. Zimmerman RH, Lounibos LP, Nishimura N, Galardo AKR, Galardo CD, Arruda ME. Nightly biting cycles of malaria vectors in a heterogeneous transmission area of eastern Amazonian Brazil. Malar J [Internet]. 2013 Jul 26;12(1):262. Available from: http://www.ncbi.nlm.nih.gov/pubmed/23890413

22. Lee $A H$, Symington LS, Fidock DA. DNA repair mechanisms and their biological roles in the malaria parasite Plasmodium falciparum. Microbiol Mol Biol Rev [Internet]. 2014;78(3):469-86. Available from: http://mmbr.asm.org/content/78/3/469.abstract

23. Baton LA, Ranford-Cartwright LC. Spreading the seeds of million-murdering death: Metamorphoses of malaria in the mosquito. Trends Parasitol. 
$2005 ; 21(12): 573-80$.

24. Frischknecht F, Matuschewski K. Plasmodium Sporozoite Biology. Cold Spring Harb Perspect Med [Internet]. 2017 Jan 20;a025478. Available from: http://perspectivesinmedicine.cshlp.org/lookup/doi/10.1101/cshperspect.a0254 78

25. Baton LA, Ranford-Cartwright LC. How do malaria ookinetes cross the mosquito midgut wall? Trends Parasitol [Internet]. 2005 Jan;21(1):22-8. Available from: http://www.ncbi.nlm.nih.gov/pubmed/15639737

26. Cowman AF, Healer J, Marapana D, Marsh K. Malaria: Biology and Disease. Cell [Internet]. $2016 \quad$ Oct;167(3):610-24. Available from: http://dx.doi.org/10.1016/j.cell.2016.07.055

27. Beeson JG, Drew DR, Boyle MJ, Feng G, Fowkes FJI, Richards JS. Merozoite surface proteins in red blood cell invasion, immunity and vaccines against malaria. FEMS Microbiol Rev [Internet]. 2016 May;40(3):343-72. Available from: http://www.ncbi.nlm.nih.gov/pubmed/26833236

28. Bannister L., Hopkins J., Fowler R., Krishna S, Mitchell G. A Brief Illustrated Guide to the Ultrastructure of Plasmodium falciparum Asexual Blood Stages. Parasitol Today [Internet]. 2000 Oct;16(10):427-33. Available from: http://linkinghub.elsevier.com/retrieve/pii/S0169475800017555

29. Bannister L, Mitchell $G$. The ins, outs and roundabouts of malaria. Trends Parasitol [Internet]. 2003 May;19(5):209-13. Available from: http://www.ncbi.nlm.nih.gov/pubmed/12763426

30. Bartoloni A, Zammarchi L. Clinical aspects of uncomplicated and severe malaria. Mediterr J Hematol Infect Dis. 2012;4(1).

31. Gachot B, Ringwald P. [Severe malaria]. Rev Prat [Internet]. 1998 Feb 1;48(3):273-8. Available from: http://ovidsp.ovid.com/ovidweb.cgi?T=JS\&NEWS=N\&PAGE=fulltext\&AN=9781 074\&D=med4

32. Trampuz A, Jereb M, Muzlovic I, Prabhu RM. Clinical review: Severe malaria. Crit Care [Internet]. 2003 Aug;7(4):315-23. Available from: http://www.ncbi.nlm.nih.gov/pubmed/12930555

33. Miller LH, Ackerman HC, Su X, Wellems TE. Malaria biology and disease pathogenesis: insights for new treatments. Nat Med [Internet]. 2013 Feb;19(2):156-67. Available from: http://www.ncbi.nlm.nih.gov/pubmed/23389616

34. Hughes KR, Biagini GA, Craig AG. Continued cytoadherence of Plasmodium falciparum infected red blood cells after antimalarial treatment. Mol Biochem Parasitol [Internet]. $2010 \quad$ Feb;169(2):71-8. Available from: http://dx.doi.org/10.1016/j.molbiopara.2009.09.007

35. Miller LH, Baruch DI, Marsh K, Doumbo OK. The pathogenic basis of malaria. Nature [Internet]. 2002 Feb 7;415(6872):673-9. Available from: http://www.ncbi.nlm.nih.gov/pubmed/11832955

36. Pouvelle B, Buffet P a, Lépolard C, Scherf a, Gysin J. Cytoadhesion of 
Plasmodium falciparum ring-stage-infected erythrocytes. Nat Med. 2000;6(11):1264-8.

37. Desai M, ter Kuile FO, Nosten F, McGready R, Asamoa K, Brabin B, et al. Epidemiology and burden of malaria in pregnancy. Lancet Infect Dis [Internet]. $2007 \quad$ Feb;7(2):93-104.

Available

from: http://www.ncbi.nlm.nih.gov/pubmed/17251080

38. Rogerson SJ, Hviid L, Duffy PE, Leke RFG, Taylor DW. Malaria in pregnancy: pathogenesis and immunity. Lancet Infect Dis [Internet]. 2007 Feb;7(2):10517. Available from: http://www.ncbi.nlm.nih.gov/pubmed/17251081

39. Beeson JG, Duffy PE. The immunology and pathogenesis of malaria during pregnancy. Curr Top Microbiol Immunol [Internet]. 2005;297:187-227. Available from: http://www.ncbi.nlm.nih.gov/pubmed/16265906

40. Menendez C, Ordi J, Ismail MR, Ventura PJ, Aponte JJ, Kahigwa E, et al. The impact of placental malaria on gestational age and birth weight. J Infect Dis [Internet]. 2000;181(5):1740-5. Available from: \%5C\%5Clarser13\%5CTIS\$\%5Clit\%5CB4000\%5CB03049.pdf

41. Meuris S, Piko BB, Eerens $P$, Vanbellinghen AM, Dramaix M, Hennart P. Gestational malaria: Assessment of its consequences on fetal growth. Am $\mathrm{J}$ Trop Med Hyg. 1993;48(5):603-9.

42. Menendez C. Malaria during pregnancy: a priority area of malaria research and control. Parasitol Today [Internet]. 1995 May;11(5):178-83. Available from: http://linkinghub.elsevier.com/retrieve/pii/0169475895801510

43. Nosten F, Rogerson SJ, Beeson JG, McGready R, Mutabingwa TK, Brabin B. Malaria in pregnancy and the endemicity spectrum: what can we learn? Trends Parasitol [Internet]. $2004 \quad$ Sep;20(9):425-32. Available from: http://www.ncbi.nlm.nih.gov/pubmed/15324733

44. Fried M, Duffy PE. Adherence of Plasmodium falciparum to chondroitin sulfate $A$ in the human placenta. Science [Internet]. 1996 Jun 7;272(5267):1502-4. Available from: http://www.ncbi.nlm.nih.gov/pubmed/8633247

45. Brabin BJ, Romagosa C, Abdelgalil S, Menéndez C, Verhoeff FH, McGready $\mathrm{R}$, et al. The sick placenta-the role of malaria. Placenta [Internet]. 2004 May;25(5):359-78. Available from: http://www.sciencedirect.com/science/article/pii/S0143400403003072

46. Schofield L, Grau GE. Immunological processes in malaria pathogenesis. Nat Rev Immunol [Internet]. 2005 Sep;5(9):722-35. Available from: http://www.ncbi.nlm.nih.gov/pubmed/16138104

47. Nwagha UI, Ugwu VO, Nwagha TU, Anyaehie BU. Asymptomatic Plasmodium parasitaemia in pregnant Nigerian women: almost a decade after Roll Back Malaria. Trans R Soc Trop Med Hyg [Internet]. 2009 Jan;103(1):16-20. Available from: http://www.ncbi.nlm.nih.gov/pubmed/18783809

48. Bulmer JN, Rasheed FN, Francis N, Morrison L, Greenwood BM. Placental malaria. I. Pathological classification. Histopathology [Internet]. 1993 Mar;22(3):211-8. Available from: http://www.ncbi.nlm.nih.gov/pubmed/8495954 
49. Neres R, Marinho CRF, Gonçalves LA, Catarino MB, Penha-Gonçalves C. Pregnancy outcome and placenta pathology in Plasmodium berghei ANKA infected mice reproduce the pathogenesis of severe malaria in pregnant women. PLoS One [Internet]. 2008;3(2):e1608. Available from: http://www.ncbi.nlm.nih.gov/pubmed/18270595

50. Sharma L, Shukla G. Placental Malaria: A New Insight into the Pathophysiology. Front Med [Internet]. 2017;4(July):1-6. Available from: http://journal.frontiersin.org/article/10.3389/fmed.2017.00117/full

51. Walter PR, Garin Y, Blot P. Placental pathologic changes in malaria. A histologic and ultrastructural study. Am J Pathol [Internet]. 1982 Dec;109(3):330-42. Available from: http://www.ncbi.nlm.nih.gov/pubmed/6758604

52. Umbers AJ, Aitken EH, Rogerson SJ. Malaria in pregnancy: Small babies, big problem. Trends Parasitol [Internet]. 2011;27(4):168-75. Available from: http://dx.doi.org/10.1016/j.pt.2011.01.007

53. Kuile FO, Rogerson SJ. Plasmodium vivax Infection during Pregnancy: An Important Problem in Need of New Solutions. 2008;46:1382-4.

54. Takem EN, D'Alessandro U. Malaria in pregnancy. Mediterr J Hematol Infect Dis [Internet]. 2013 Jan 2;5(1):e2013010. Available from: http://www.mjhid.org/article/view/2013.010

55. Rao AJ. Regulation of Growth and Function of Lifeline Placenta. Kaul SK, editor. MGM J Med Sci [Internet]. 2014;1(September):139-42. Available from: http://www.jaypeejournals.com/eJournals/ShowText.aspx?ID=6331\&Type=FRE $E \& T Y P=T O P \& I N=\sim / e J o u r n a l s / i m a g e s / J P L O G O . g i f \& I I D=478 \& i s P D F=Y E S$

56. Rogerson SJ, Desai M, Mayor A, Sicuri E, Taylor SM, van Eijk AM. Burden, pathology, and costs of malaria in pregnancy: new developments for an old problem. Lancet Infect Dis [Internet]. 2018;18(4):e107-18. Available from: http://linkinghub.elsevier.com/retrieve/pii/S1473309918300665

57. Khunrae P, Dahlbäck M, Nielsen MA, Andersen G, Ditlev SB, Resende M, et al. Full-length recombinant Plasmodium falciparum VAR2CSA binds specifically to CSPG and induces potent parasite adhesion-blocking antibodies. $J$ Mol Biol [Internet]. 2010 Apr 2;397(3):826-34. Available from: http://dx.doi.org/10.1016/j.jmb.2010.01.040

58. Tuikue Ndam NG, Salanti A, Bertin G, Dahlbäck M, Fievet N, Turner L, et al. High level of var2csa transcription by Plasmodium falciparum isolated from the placenta. J Infect Dis [Internet]. 2005 Jul 15;192(2):331-5. Available from: https://academic.oup.com/jid/article-lookup/doi/10.1086/430933

59. Wahlgren M, Goel S, Akhouri RR. Variant surface antigens of Plasmodium falciparum and their roles in severe malaria. Nat Rev Microbiol [Internet]. 2017 Aug;15(8):479-91.

Available from: http://www.ncbi.nlm.nih.gov/pubmed/28603279\%5Cnhttp://www.nature.com/doi finder/10.1038/nrmicro.2017.47

60. Costa FTM, Avril M, Nogueira PA, Gysin J. Cytoadhesion of Plasmodium falciparum-infected erythrocytes and the infected placenta: a two-way pathway. 
Brazilian J Med Biol Res $=$ Rev Bras Pesqui medicas e Biol [Internet]. 2006 Dec;39(12):1525-36. Available

from: http://www.ncbi.nlm.nih.gov/pubmed/17160261

61. Bentley G a, Gamain B. How does Plasmodium falciparum stick to CSA? Let's see in the crystal. Nat Struct Mol Biol [Internet]. 2008;15(9):895-7. Available from: http://www.ncbi.nlm.nih.gov/pubmed/18769465

62. Rovira-Vallbona E, Monteiro I, Bardají A, Serra-Casas E, Neafsey DE, Quelhas $\mathrm{D}$, et al. VAR2CSA signatures of high Plasmodium falciparum parasitemia in the placenta. PLoS One [Internet]. 2013;8(7):e69753. Available from: http://www.ncbi.nlm.nih.gov/pubmed/23936092

63. Dimasuay KG, Boeuf $P$, Powell TL, Jansson T. Placental Responses to Changes in the Maternal Environment Determine Fetal Growth. Front Physiol [Internet]. 2016;7(JAN):12. Available

from: http://www.ncbi.nlm.nih.gov/pubmed/26858656

64. Mens PF, Bojtor EC, Schallig HDFH. Molecular interactions in the placenta during malaria infection. Eur J Obstet Gynecol Reprod Biol [Internet]. 2010;152(2):126-32. Available from: http://dx.doi.org/10.1016/j.ejogrb.2010.05.013

65. Suguitan AL, Leke RGF, Fouda G, Zhou A, Thuita L, Metenou S, et al. Changes in the levels of chemokines and cytokines in the placentas of women with Plasmodium falciparum malaria. J Infect Dis [Internet]. 2003 Oct 1;188(7):1074-82. Available http://jid.oxfordjournals.org/lookup/doi/10.1086/378500

66. Abrams ET, Brown H, Chensue SW, Turner GDH, Tadesse E, Lema VM, et al. Host Response to Malaria During Pregnancy: Placental Monocyte Recruitment Is Associated with Elevated Chemokine Expression. J Immunol [Internet]. 2003 Mar 1;170(5):2759-64. Available from: http://www.jimmunol.org/content/170/5/2759\%5Cnhttp://www.jimmunol.org/cont ent/170/5/2759

67. Manirakiza A, Serdouma E, Ngbalé RN, Moussa S, Gondjé S, Degana RM, et al. A brief review on features of falciparum malaria during pregnancy. J Public Health Africa [Internet]. 2017 Dec 31;8(2):668. Available from: http://www.ncbi.nlm.nih.gov/pubmed/29456824

68. Schofield L. Intravascular infiltrates and organ-specific inflammation in malaria pathogenesis. Immunol Cell Biol [Internet]. 2007;85(2):130-7. Available from: http://www.ncbi.nlm.nih.gov/pubmed/17344907

69. Fried M, Muga RO, Misore a O, Duffy PE. Malaria elicits type 1 cytokines in the human placenta: IFN-gamma and TNF-alpha associated with pregnancy outcomes. J Immunol [Internet]. 1998 Mar 1;160(5):2523-30. Available from: http://www.ncbi.nlm.nih.gov/pubmed/9498798

70. Gamain B, Gratepanche S, Miller LH, Baruch DI. Molecular basis for the dichotomy in Plasmodium falciparum adhesion to CD36 and chondroitin sulfate A. Proc Natl Acad Sci U S A [Internet]. 2002 Jul 23;99(15):10020-4. Available from: http://www.ncbi.nlm.nih.gov/pubmed/12096191 
71. Lyall F. The human placental bed revisited. Placenta. 2002;23(8-9):555-62.

72. Red-Horse K, Zhou Y, Genbacev O, Prakobphol A, Foulk R, McMaster M, et al. Trophoblast differentiation during embryo implantation and formation of the maternal-fetal interface. J Clin Invest. 2004;114(6):744-54.

73. Vause S, Saroya DK. Functions of the placenta. Anaesth Intensive Care Med [Internet]. $2005 \quad$ Mar;6(3):77-80. Available from: http://linkinghub.elsevier.com/retrieve/pii/S1472029906700546

74. Thellin O, Heinen E. Pregnancy and the immune system: between tolerance and rejection. Toxicology [Internet]. 2003 Apr 1;185(3):179-84. Available from: http://www.ncbi.nlm.nih.gov/pubmed/12581692

75. Gude NM, Roberts CT, Kalionis B, King RG. Growth and function of the normal human placenta. Thromb Res [Internet]. 2004 Jan;114(5-6):397-407. Available from: http://linkinghub.elsevier.com/retrieve/pii/S0049384804003421

76. da Anunciação A, Mess AM, Orechio D, Aguiar BA, Favaron PO, Miglino MA. Extracellular matrix in epitheliochorial, endotheliochorial and haemochorial placentation and its potential application for regenerative medicine. Reprod Domest Anim [Internet]. 2017 Feb;52(1):3-15. Available from: http://www.ncbi.nlm.nih.gov/pubmed/27925305

77. Bedzhov I, Zernicka-Goetz M. Cell death and morphogenesis during early mouse development: Are they interconnected? BioEssays. 2015;37(4):372-8.

78. Dey SK, Lim H, Das SK, Reese J, Paria BC, Daikoku T, et al. Molecular cues to implantation. Endocr Rev [Internet]. 2004 Jun;25(3):341-73. Available from: https://academic.oup.com/edrv/article-lookup/doi/10.1210/er.2003-0020

79. Cross JC. How to make a placenta: mechanisms of trophoblast cell differentiation in mice--a review. Placenta [Internet]. 2005 Apr;26 Suppl A(SUPPL.):S3-9. Available http://www.ncbi.nlm.nih.gov/pubmed/15837063

80. Hu D, Cross JC. Development and function of trophoblast giant cells in the rodent placenta. Int J Dev Biol. 2010;54(2-3):341-54.

81. El-Hashash AHK, Warburton D, Kimber SJ. Genes and signals regulating murine trophoblast cell development. Mech Dev [Internet]. 2010;127(1-2):120. Available from: http://dx.doi.org/10.1016/j.mod.2009.09.004

82. Rossant J, Cross JC. Placental development: lessons from mouse mutants. Nat Rev Genet [Internet]. 2001 Jul;2(7):538-48. Available from: http://www.nature.com/doifinder/10.1038/35080570

83. Cross JC. Genetic insights into trophoblast differentiation and placental morphogenesis. Semin Cell Dev Biol [Internet]. 2000 Apr;11(2):105-13. Available from: http://www.ncbi.nlm.nih.gov/pubmed/10873707

84. Chucri TM, Monteiro JM, Lima AR, Salvadori MLB, Kfoury JR, Miglino MA. A review of immune transfer by the placenta. J Reprod Immunol [Internet]. 2010 Dec;87(1-2):14-20. Available from: http://dx.doi.org/10.1016/j.jri.2010.08.062

85. Maltepe E, Fisher SJ. Placenta: the forgotten organ. Annu Rev Cell Dev Biol 
[Internet].

$2015 ; 31(1): 523-52$.

Available

from:

http://www.ncbi.nlm.nih.gov/pubmed/26443191

86. Simmons DG, Natale DRC, Begay V, Hughes M, Leutz A, Cross JC. Early patterning of the chorion leads to the trilaminar trophoblast cell structure in the placental labyrinth. Development [Internet]. 2008 May 14;135(12):2083-91. Available from: http://www.ncbi.nlm.nih.gov/pubmed/21763191

87. Yamashita K, Yoshioka Y, Higashisaka K, Mimura K, Morishita Y, Nozaki M, et al. Silica and titanium dioxide nanoparticles cause pregnancy complications in mice. Nat Nanotechnol [Internet]. 2011;6(5):321-8. Available from: http://dx.doi.org/10.1038/nnano.2011.41

88. Watson ED, Cross JC. Development of structures and transport functions in the mouse placenta. Physiology (Bethesda) [Internet]. 2005 Jun;20:180-93. Available from: http://www.ncbi.nlm.nih.gov/pubmed/15888575

89. Du M-R, Wang S-C, Li D-J. The integrative roles of chemokines at the maternal-fetal interface in early pregnancy. Cell Mol Immunol [Internet]. 2014 Sep;11(5):438-48. Available from: http://www.ncbi.nlm.nih.gov/pubmed/25109684

90. Mizushima N, Levine B. Autophagy in mammalian development and differentiation. Nat Cell Biol [Internet]. 2010 Sep;12(9):823-30. Available from: http://www.ncbi.nlm.nih.gov/pubmed/20811354

91. He C, Klionsky DJ. Regulation mechanisms and signaling pathways of autophagy. Annu Rev Genet [Internet]. 2009;43(68):67-93. Available from: http://www.ncbi.nlm.nih.gov/pmc/articles/PMC2831538/

92. Klionsky DJ. Autophagy revisited: A conversation with Christian de Duve. Autophagy. 2008;4(6):740-3.

93. Lyndsay Murrow \& Jayanta Debnath. Autophagy As A Stress Response And Quality Control Mechanism-Implications for Cell Injury and Human Disease. Annu Rev Pathol. 2013;(2):105-37.

94. Boya P, Gonza R, Casares N, Perfettini J, Dessen P, Larochette N, et al. Inhibition of Macroautophagy Triggers Apoptosis. Mol Cell Biol. $2005 ; 25(3): 1025-40$.

95. Arroyo DS, Gaviglio EA, Peralta Ramos JM, Bussi C, Rodriguez-Galan MC, Iribarren P. Autophagy in inflammation, infection, neurodegeneration and cancer. Int Immunopharmacol. 2014;18(1):55-65.

96. Limbergen J Van, Stevens C, Nimmo ER, Wilson DC, Satsangi J. Autophagy: from basic science to clinical application. Nature [Internet]. 2009;2(4):315-30. Available from: http://dx.doi.org/10.1038/mi.2009.20

97. Rut Valdor \& Fernando Macian. Autophagy and the Regulation of the Immune Response. Pharmacol Res. 2012;66(6):475-83.

98. Boya P, Reggiori F, Codogno P. Emerging regulation and functions of autophagy. Nat Cell Biol [Internet]. 2013 Jul;15(7):713-20. Available from: http://www.ncbi.nlm.nih.gov/pubmed/23817233 
99. Wei Y, Pattingre S, Sinha S, Bassik M, Levine B. JNK1-mediated phosphorylation of $\mathrm{Bcl}-2$ regulates starvation-induced autophagy. Mol Cell [Internet]. 2008 Jun 20;30(6):678-88. Available from: http://www.ncbi.nlm.nih.gov/pubmed/18570871

100. Zalckvar E, Berissi H, Mizrachy L, Idelchuk Y, Koren I, Eisenstein M, et al. DAP-kinase-mediated phosphorylation on the $\mathrm{BH} 3$ domain of beclin 1 promotes dissociation of beclin 1 from $\mathrm{Bcl}-\mathrm{XL}$ and induction of autophagy. EMBO Rep [Internet]. 2009 Mar;10(3):285-92. Available from: http://www.ncbi.nlm.nih.gov/pubmed/19180116

101. Russell RC, Yuan H-X, Guan K-L. Autophagy regulation by nutrient signaling. Cell Res [Internet]. 2014;24(1):42-57. Available from: http://www.ncbi.nlm.nih.gov/pubmed/24343578

102. Mizushima N, Yoshimori T, Ohsumi Y. The Role of Atg Proteins in Autophagosome Formation. Annu Rev Cell Dev Biol [Internet]. 2011;27(1):107-32. Available from: http://www.annualreviews.org/doi/10.1146/annurev-cellbio-092910-154005

103. Mizushima N, Noda T, Yoshimori T, Tanaka Y, Ishii T, George MD, et al. A protein conjugation system essential for autophagy. Nature [Internet]. 1998 Sep 24;395(6700):395-8. Available from: http://www.ncbi.nlm.nih.gov/entrez/query.fcgi?cmd=Retrieve\&db=PubMed\&dop $\mathrm{t}=$ Citation\&list_uids=9759731\%5Cnhttp://www.nature.com/nature/journal/v395/ n6700/pdf/395395a0.pdf

104. Kabeya Y, Mizushima N, Ueno T, Yamamoto A, Kirisako T, Noda T, et al. LC3, a mammalian homologue of yeast Apg8p, is localized in autophagosome membranes after processing. EMBO J [Internet]. 2000 Nov 1;19(21):5720-8. Available from: http://www.ncbi.nlm.nih.gov/pubmed/11060023

105. Ichimura $Y$, Kirisako T, Takao T, Satomi $Y$, Shimonishi $Y$, Ishihara N, et al. A ubiquitin-like system mediates protein lipidation. Nature [Internet]. 2000 Nov 23;408(6811):488-92. Available from: http://www.ncbi.nlm.nih.gov/pubmed/11100732

106. Fujita $\mathrm{N}$, Itoh $\mathrm{T}$, Omori $\mathrm{H}$, Fukuda $\mathrm{M}$, Noda $\mathrm{T}$, Yoshimori T. The Atg16L complex specifies the site of LC3 lipidation for membrane biogenesis in autophagy. Mol Biol Cell [Internet]. 2008 May;19(5):2092-100. Available from: http://www.ncbi.nlm.nih.gov/pubmed/18321988

107. Chunli Liu, Yanqin Gao, John Barret and $\mathrm{BH}$. Autophagy and protein aggregation after brain ischemia. J Neurochem. 2010;115(1):68-78.

108. Scherz-shouval R, Shvets E, Fass E, Shorer H, Gil L, Elazar Z. autophagy and specifically regulate the activity. EMBO J. 2007;26(7):1749-60.

109. Karanasios E, Ktistakis NT. Autophagy at the Cell, Tissue and Organismal Level [Internet]. Cham: Springer International Publishing; 2016. Available from: http://link.springer.com/10.1007/978-3-319-33145-4

110. Wu J, Dang Y, Su W, Liu C, Ma H, Shan Y, et al. Molecular cloning and characterization of rat LC3A and LC3B--two novel markers of autophagosome. Biochem Biophys Res Commun. 2006;339(1):437-42. 
111. Johansen $T$, Lamark T. Selective autophagy mediated by autophagic adapter proteins. Autophagy [Internet]. 2011 Mar;7(3):279-96. Available from: http://www.ncbi.nlm.nih.gov/pubmed/21189453

112. Rogov V, Dötsch V, Johansen $T$, Kirkin V. Interactions between autophagy receptors and ubiquitin-like proteins form the molecular basis for selective autophagy. Mol Cell [Internet]. 2014 Jan 23;53(2):167-78. Available from: http://www.ncbi.nlm.nih.gov/pubmed/24462201

113. Bjørkøy G, Lamark $T$, Brech $A$, Outzen $H$, Perander $M$, Overvatn $A$, et al. p62/SQSTM1 forms protein aggregates degraded by autophagy and has a protective effect on huntingtin-induced cell death. J Cell Biol [Internet]. 2005 Nov 21;171(4):603-14. Available from: http://www.ncbi.nlm.nih.gov/pubmed/16286508

114. Glick D, Barth S, Macleod KF. Autophagy: cellular and molecular mechanisms. J Pathol [Internet]. 2010 May;221(1):3-12. Available from: papers://1342abd5e320-4e10-a9b6-f8497f56318b/Paper/p11731

115. Marzban H, Del Bigio MR, Alizadeh J, Ghavami S, Zachariah RM, Rastegar M. Cellular commitment in the developing cerebellum. Front Cell Neurosci [Internet]. 2014;8(January):450. Available from: http://journal.frontiersin.org/article/10.3389/fncel.2014.00450/abstract

116. Sato M, Sato K. Maternal inheritance of mitochondrial DNA: degradation of paternal mitochondria by allogeneic organelle autophagy, allophagy. Autophagy [Internet]. 2012 Mar;8(3):424-5. Available from: http://www.ncbi.nlm.nih.gov/pubmed/22302002

117. Nakashima A, Aoki A, Kusabiraki T, Shima T, Yoshino O, Cheng S Bin, et al. Role of autophagy in oocytogenesis, embryogenesis, implantation, and pathophysiology of pre-eclampsia. J Obstet Gynaecol Res. 2017;43(4):633-43.

118. Saito S, Nakashima A. A review of the mechanism for poor placentation in early-onset preeclampsia: The role of autophagy in trophoblast invasion and vascular remodeling. J Reprod Immunol [Internet]. 2014;101-102(1):80-8. Available from: http://dx.doi.org/10.1016/j.jri.2013.06.002

119. Sisti G, Kanninen TT, Ramer I, Witkin SS. Interaction between the inducible 70$\mathrm{kDa}$ heat shock protein and autophagy: effects on fertility and pregnancy. Cell Stress Chaperones. 2015;20(5):753-8.

120. Kanninen TT, de Andrade Ramos BR, Witkin SS. The role of autophagy in reproduction from gametogenesis to parturition. Eur J Obstet Gynecol Reprod Biol [Internet]. $2013 \quad \mathrm{Nov} ; 171(1): 3-8 . \quad$ Available from: http://dx.doi.org/10.1016/j.ejogrb.2013.07.020

121. Saito S, Nakashima A. Review: The role of autophagy in extravillous trophoblast function under hypoxia. Placenta [Internet]. 2013;34(SUPPL):S7984. Available from: http://dx.doi.org/10.1016/j.placenta.2012.11.026

122. Tsukamoto S, Kuma A, Murakami M, Kishi C, Yamamoto A, Mizushima N. Autophagy is essential for preimplantation development of mouse embryos. Science [Internet]. 2008 Jul 4;321(5885):117-20. Available from: http://www.sciencemag.org/cgi/doi/10.1126/science.1154822 
123. Stitzel ML, Seydoux G. Regulation of the oocyte-to-zygote transition. Science [Internet]. $2007 \quad$ Apr 20;316(5823):407-8. Available from: http://www.ncbi.nlm.nih.gov/pubmed/17446393

124. Singh R, Kaushik S, Wang Y, Xiang Y, Novak I, Komatsu M, et al. Autophagy regulates lipid metabolism. Nature [Internet]. 2009;458(7242):1131-5. Available from: http://www.pubmedcentral.nih.gov/articlerender.fcgi?artid=2676208\&tool=pmce ntrez\&rendertype=abstract

125. Signorelli $P$, Avagliano L, Virgili E, Gagliostro V, Doi $P$, Braidotti $P$, et al. Autophagy in term normal human placentas. Placenta [Internet]. 2011;32(6):482-5. Available from: http://dx.doi.org/10.1016/j.placenta.2011.03.005

126. Avagliano L, Virgili E, Garò C, Quadrelli F, Doi P, Samaja M, et al. Autophagy and human parturition: Evaluation of LC3 expression in placenta from spontaneous or medically induced onset of labor. Biomed Res Int. 2013;2013.

127. Brickle A, Tran HT, Lim R, Liong S, Lappas M. Autophagy, which is decreased in labouring fetal membranes, regulates IL-1 $\beta$ production via the inflammasome. Placenta [Internet]. 2015 Dec;36(12):1393-404. Available from: http://linkinghub.elsevier.com/retrieve/pii/S0143400415300758

128. Levine B, Mizushima N, Virgin HW. Autophagy in immunity and inflammation. Nature. 2011;469(7330):323-35.

129. Cadwell K. Crosstalk between autophagy and inflammatory signalling pathways: balancing defence and homeostasis. Nat Rev Immunol [Internet]. 2016;16(11):661-75. Available from: http://www.nature.com/doifinder/10.1038/nri.2016.100

130. Shibutani ST, Saitoh T, Nowag H, Munz C, Yoshimori T. Autophagy and autophagy-related proteins in the immune system. Nat Immunol [Internet]. 2015;16(10):1014-24.

http://www.ncbi.nlm.nih.gov/pubmed/26382870

131. Randow F, Youle RJ. Self and nonself: how autophagy targets mitochondria and bacteria. Cell Host Microbe [Internet]. 2014 Apr 9;15(4):403-11. Available from: http://dx.doi.org/10.1016/j.chom.2014.03.012

132. Shi C-S, Kehrl JH. TRAF6 and A20 regulate lysine 63-linked ubiquitination of Beclin-1 to control TLR4-induced autophagy. Sci Signal [Internet]. 2010 May 25;3(123):ra42.

Available from: http://www.ncbi.nlm.nih.gov/entrez/query.fcgi?cmd=Retrieve\&db=PubMed\&dop $\mathrm{t}=$ Citation\&list_uids $=20501938$

133. Xu Y, Jagannath C, Liu X-D, Sharafkhaneh A, Kolodziejska KE, Eissa NT. Tolllike receptor 4 is a sensor for autophagy associated with innate immunity. Immunity [Internet]. 2007 Jul;27(1):135-44. Available from: http://www.ncbi.nlm.nih.gov/pubmed/17658277

134. Saitoh T, Akira S. Regulation of innate immune responses by autophagyrelated proteins. J Cell Biol [Internet]. 2010 Jun 14;189(6):925-35. Available from: http://www.jcb.org/lookup/doi/10.1083/jcb.201002021 
135. Into T, Inomata M, Takayama E, Takigawa T. Autophagy in regulation of Tolllike receptor signaling. Cell Signal [Internet]. 2012 Jun;24(6):1150-62. Available from: http://dx.doi.org/10.1016/j.cellsig.2012.01.020

136. Lupfer C, Thomas PG, Anand PK, Vogel P, Milasta S, Martinez J, et al. Receptor interacting protein kinase 2-mediated mitophagy regulates inflammasome activation during virus infection. Nat Immunol [Internet]. 2013 May;14(5):480-8. Available from: http://dx.doi.org/10.1038/ni.2563

137. Nakahira K, Haspel JA, Rathinam VAK, Lee S-J, Dolinay T, Lam HC, et al. Autophagy proteins regulate innate immune responses by inhibiting the release of mitochondrial DNA mediated by the NALP3 inflammasome. Nat Immunol [Internet]. $2011 \quad$ Mar;12(3):222-30. Available from: http://www.pubmedcentral.nih.gov/articlerender.fcgi ?artid=3079381\&tool=pmce ntrez\&rendertype=abstract

138. Razani B, Feng C, Coleman T, Emanuel R, Wen H, Hwang S, et al. Autophagy links inflammasomes to atherosclerotic progression. Cell Metab [Internet]. 2012 Apr 4;15(4):534-44. Available from: http://dx.doi.org/10.1016/j.cmet.2012.02.011

139. Wen $H$, Gris D, Lei $Y$, Jha S, Zhang L, Huang MT-H, et al. Fatty acid-induced NLRP3-ASC inflammasome activation interferes with insulin signaling. Nat Immunol [Internet]. 2011 May;12(5):408-15. Available from: http://dx.doi.org/10.1038/ni.2022

140. Chaikitgosiyakul S, Rijken MJ, Muehlenbachs A, Lee SJ, Chaisri U, Viriyavejakul $\mathrm{P}$, et al. A morphometric and histological study of placental malaria shows significant changes to villous architecture in both Plasmodium falciparum and Plasmodium vivax infection. Malar J [Internet]. 2014 Jan 4;13:4. Available from: http://www.pubmedcentral.nih.gov/articlerender.fcgi $?$ artid=3900675\&tool=pmce ntrez\&rendertype=abstract

141. Fried M, Kurtis JD, Swihart B, Pond-Tor S, Barry A, Sidibe Y, et al. Systemic Inflammatory Response to Malaria During Pregnancy Is Associated With Pregnancy Loss and Preterm Delivery. Clin Infect Dis [Internet]. 2017;(October):16-8. Available from: http://www.ncbi.nlm.nih.gov/pubmed/29020221\%0Ahttp://academic.oup.com/ci d/article/doi/10.1093/cid/cix623/3980252/Systemic-Inflammatory-Response-toMalaria-During

142. Ataíde R, Murillo O, Dombrowski JG, Souza RM, Lima FA, Lima GFMC, et al. Malaria in Pregnancy Interacts with and Alters the Angiogenic Profiles of the Placenta. Rodrigues MM, editor. PLoS Negl Trop Dis [Internet]. 2015 Jun 19;9(6):e0003824. Available from: http://dx.plos.org/10.1371/journal.pntd.0003824

143. Marinho CRF, Neres R, Epiphanio S, Gonçalves LA, Catarino MB, PenhaGonçalves C. Recrudescent Plasmodium berghei from pregnant mice displays enhanced binding to the placenta and induces protection in multigravida. PLoS One. 2009;4(5).

144. Barboza R, Lima FA, Reis AS, Murillo OJ, Peixoto EPM, Bandeira CL, et al. 
TLR4-Mediated Placental Pathology and Pregnancy Outcome in Experimental Malaria. Sci Rep. 2017;7(1):1-12.

145. Barboza R, Reis AS, da Silva LG, Hasenkamp L, Pereira KRB, Camara NOS, et al. MyD88 Signaling Is Directly Involved in the Development of Murine Placental Malaria. Infect Immun [Internet]. 2014 Feb 1;82(2):830-8. Available from: http://iai.asm.org/cgi/doi/10.1128/IAl.01288-13

146. Janse CJ, Van Vianen PH. Flow cytometry in malaria detection. Methods Cell Biol [Internet]. 1994;42 Pt B:295-318. Available from: http://www.ncbi.nlm.nih.gov/pubmed/7533245

147. Freyre A, Falcón J, Méndez J, Rodriguez A, Correa L, González M. Refinement of the mouse model of congenital toxoplasmosis. Exp Parasitol [Internet]. 2006 Jul;113(3):154-60. Available http://linkinghub.elsevier.com/retrieve/pii/S0014489405003498

from:

148. Schmalbruch $\mathrm{H}$. The early changes in experimental myopathy induced by chloroquine and chlorphentermine. J Neuropathol Exp Neurol. 1980 Jan;39(1):65-81.

149. Perry CN, Kyoi S, Hariharan N, Takagi H, Sadoshima J, Gottlieb RA. Novel methods for measuring cardiac autophagy in vivo. Methods Enzymol [Internet]. 2009;453:325-42. Available from: http://linkinghub.elsevier.com/retrieve/pii/S0076687908040160

150. Jensen EB, Gundersen HJG, Osterby R. Determination of membrane thickness distribution from orthogonal intercepts. J Microsc [Internet]. 1979 Jan;115(1):19-33. Available from: http://www.ncbi.nlm.nih.gov/pubmed/423237

151. Bandeira CL, Urban Borbely A, Pulcineli Vieira Francisco R, Schultz R, Zugaib $\mathrm{M}$, Bevilacqua $\mathrm{E}$. Tumorigenic factor CRIPTO-1 is immunolocalized in extravillous cytotrophoblast in placenta creta. Biomed Res Int [Internet]. 2014;2014:892856. Available

from: http://www.ncbi.nlm.nih.gov/pubmed/25165718

152. Hviid L, Marinho CRF, Staalsoe T, Penha-Gonçalves C. Of mice and women: rodent models of placental malaria. Trends Parasitol [Internet]. 2010 Aug;26(8):412-9. Available from: http://linkinghub.elsevier.com/retrieve/pii/S1471492210000863

153. Ioannidis LJ, Nie CQ, Hansen DS. The role of chemokines in severe malaria: more than meets the eye. Parasitology. 2014;141(5):602-13.

154. Leoni S, Buonfrate D, Angheben A, Gobbi F, Bisoffi Z. The hyper-reactive malarial splenomegaly: a systematic review of the literature. Malar J. 2015 Dec;14(1):185.

155. Hansen DS, Siomos MA, de Koning-Ward T, Buckingham L, Crabb BS, Schofield L. CD1d-restricted NKT cells contribute to malarial splenomegaly and enhance parasite-specific antibody responses. Eur $\mathrm{J}$ Immunol. 2003;33(9):2588-98.

156. Buffet P a, Safeukui I, Deplaine G, Brousse V, Prendki V, Thellier M, et al. The pathogenesis of Plasmodium falciparum malaria in humans: insights from 
splenic physiology. Blood [Internet]. 2011 Jan 13;117(2):381-92. Available from: http://www.ncbi.nlm.nih.gov/pubmed/20852127

157. Rodrigues-Duarte L, de Moraes LV, Barboza R, Marinho CRF, Franke-Fayard $B$, Janse $\mathrm{CJ}$, et al. Distinct placental malaria pathology caused by different Plasmodium berghei lines that fail to induce cerebral malaria in the C57BL/6 mouse. Malar J [Internet]. 2012 Jul 16;11:231. Available from: http://www.ncbi.nlm.nih.gov/pubmed/22799533

158. Briand V, Saal J, Ghafari C, Huynh B-T, Fievet N, Schmiegelow C, et al. Fetal Growth Restriction Is Associated With Malaria in Pregnancy: A Prospective Longitudinal Study in Benin. J Infect Dis. 2016 Aug;214(3):417-25.

159. Djontu JC, Siewe Siewe S, Mpeke Edene YD, Nana BC, Chomga Foko EV, Bigoga JD, et al. Impact of placental Plasmodium falciparum malaria infection on the Cameroonian maternal and neonate's plasma levels of some cytokines known to regulate T cells differentiation and function. Malar J. 2016;15(1):1-11.

160. Moore KA, Simpson JA, Wiladphaingern J, Min AM, Pimanpanarak M, Paw $\mathrm{MK}$, et al. Influence of the number and timing of malaria episodes during pregnancy on prematurity and small-for-gestational-age in an area of low transmission. BMC Med [Internet]. 2017 Jun 21 [cited 2017 Dec 3];15(1):117. Available from: http://www.ncbi.nlm.nih.gov/pubmed/28633672

161. Van Zon AAJC, Eling WMC. Depressed malarial immunity in pregnant mice. Infect Immun. 1980;28(2):630-2.

162. Pásztor N, Sikovanyecz J, Keresztúri A, Kozinszky Z, Németh G. Evaluation of the relation between placental weight and placental weight to foetal weight ratio and the causes of stillbirth: a retrospective comparative study. J Obstet Gynaecol (Lahore) [Internet]. 2018;38(1):74-80. Available from: https://doi.org/10.1080/01443615.2017.1349084

163. Hayward CE, Lean S, Sibley CP, Jones RL, Wareing M, Greenwood SL, et al. Placental adaptation: What can we learn from Birthweight:placental weight ratio? Front Physiol. 2016;7(FEB):1-13.

164. Cetin I, Foidart J-M, Miozzo M, Raun T, Jansson T, Tsatsaris V, et al. Fetal growth restriction: a workshop report. Placenta [Internet]. 2004 Sep;25(89):753-7. Available http://linkinghub.elsevier.com/retrieve/pii/S014340040400058X

165. Coan PM, Ferguson-Smith AC, Burton GJ. Developmental dynamics of the definitive mouse placenta assessed by stereology. Biol Reprod [Internet]. 2004 Jun;70(6):1806-13. Available from: https://academic.oup.com/biolreprod/articlelookup/doi/10.1095/biolreprod.103.024166

166. Maltepe E, Fisher SJ. Placenta: The Forgotten Organ. Annu Rev Cell Dev Biol [Internet]. 2015;31(1):523-52. Available from: http://www.annualreviews.org/doi/10.1146/annurev-cellbio-100814-125620

167. Dilworth MR, Sibley CP. Review: Transport across the placenta of mice and women. Placenta [Internet]. 2013;34(SUPPL):S34-9. Available from: http://dx.doi.org/10.1016/j.placenta.2012.10.011 
168. Sandovici I, Hoelle K, Angiolini E, Constância M. Placental adaptations to the maternal-fetal environment: Implications for fetal growth and developmental programming. Reprod Biomed Online. 2012;25(1):68-89.

169. Watson E, Cross J. Development of Structures and Transport Functions in the Mouse Placenta. Physiology. 2005;20:180-93.

170. Coan PM, Ferguson-Smith AC, Burton GJ. Ultrastructural changes in the interhaemal membrane and junctional zone of the murine chorioallantoic placenta across gestation. J Anat. 2005 Dec;207(6):783-96.

171. Zamudio S, Baumann MU, Illsley NP. Effects of chronic hypoxia in vivo on the expression of human placental glucose transporters. Placenta. 2006 Jan;27(1):49-55.

172. Zamudio S, Torricos T, Fik E, Oyala M, Echalar L, Pullockaran J, et al. Hypoglycemia and the Origin of Hypoxia-Induced Reduction in Human Fetal Growth. Zhou W-L, editor. PLoS One. 2010 Jan;5(1):e8551.

173. James LA, Zhang J, Byrne CD, Nicholas Hales C. Effects of maternal iron restriction in the rat on hypoxia-induced gene expression and fetal metabolite levels. Br J Nutr. 2001 Feb;85(02):193.

174. Boeuf P, Aitken EH, Chandrasiri U, Chua CLL, Mclnerney B, McQuade L, et al. Plasmodium falciparum Malaria Elicits Inflammatory Responses that Dysregulate Placental Amino Acid Transport. PLoS Pathog. 2013;9(2):1-12.

175. Dimasuay KG, Aitken EH, Rosario F, Njie M, Glazier J, Rogerson SJ, et al. Inhibition of placental mTOR signaling provides a link between placental malaria and reduced birthweight. BMC Med [Internet]. 2017;1-11. Available from: http://dx.doi.org/10.1186/s12916-016-0759-3

176. Sferruzzi-Perri AN, Vaughan OR, Coan PM, Suciu MC, Darbyshire R, Constancia $M$, et al. Placental-specific lgf2 deficiency alters developmental adaptations to undernutrition in mice. Endocrinology. 2011;152(8):3202-12.

177. Redline RW, Chernicky CL, Tan HQ, Ilan J, Ilan J. Differential expression of insulin-like growth factor-II in specific regions of the late (post day 9.5) murine placenta. Mol Reprod Dev [Internet]. 1993 Oct;36(2):121-9. Available from: http://www.ncbi.nlm.nih.gov/pubmed/8257562

178. Oh-McGinnis R, Bogutz AB, Lefebvre L. Partial loss of Ascl2 function affects all three layers of the mature placenta and causes intrauterine growth restriction. Dev Biol [Internet]. 2011 Mar 15;351(2):277-86. Available from: http://dx.doi.org/10.1016/j.ydbio.2011.01.008

179. Hirsch E, Wang $\mathrm{H}$. The Molecular Pathophysiology of Bacterially Induced Preterm Labor: Insights From the Murine Model. J Soc Gynecol Investig. 2005 Apr;12(3):145-55.

180. Krishnan L, Nguyen T, McComb S. From mice to women: The conundrum of immunity to infection during pregnancy. J Reprod Immunol [Internet]. 2013;97(1):62-73. Available from: http://dx.doi.org/10.1016/j.jri.2012.10.015

181. Ofori MF, Lamptey H, Dickson EK, Kyei-Baafour E, Hviid L. The Etiology of Placental Plasmodium Falciparum Malaria in African Women. J Infect Dis 
[Internet]. $2018 \quad$ Mar 22;(June):1-5. Available from: http://www.ncbi.nlm.nih.gov/pubmed/29579263

182. Bowen JM, Chamley L, Keelan JA, Mitchell MD. Cytokines of the placenta and extra-placental membranes: Roles and regulation during human pregnancy and parturition. Placenta. 2002;23(4):257-73.

183. Fievet N, Moussa M, Tami G, Maubert B, Cot M, Deloron P, et al. Plasmodium falciparum induces a Th1/Th2 disequilibrium, favoring the Th1-type pathway, in the human placenta. J Infect Dis [Internet]. 2001;183(10):1530-4. Available from: http://www.ncbi.nlm.nih.gov/pubmed/11319691

184. Dorman EK, Shulman CE, Kingdom J, Bulmer JN, Mwendwa J, Peshu N, et al. Impaired uteroplacental blood flow in pregnancies complicated by falciparum malaria. Ultrasound Obstet Gynecol [Internet]. 2002 Feb;19(2):165-70. Available from: http://www.ncbi.nlm.nih.gov/pubmed/11876809

185. Silver KL, Zhong K, Leke RGF, Taylor DW, Kain KC. Dysregulation of angiopoietins is associated with placental malaria and low birth weight. PLoS One [Internet]. 2010 Mar 1;5(3):e9481. Available from: http://www.ncbi.nlm.nih.gov/pubmed/20208992

186. Conroy AL, Silver KL, Zhong K, Rennie M, Ward P, Sarma JV, et al. Complement activation and the resulting placental vascular insufficiency drives fetal growth restriction associated with placental malaria. Cell Host Microbe [Internet]. 2013;13(2):215-26. Available from: http://dx.doi.org/10.1016/j.chom.2013.01.010

187. Dobaño C, Berthoud T, Manaca MN, Nhabomba A, Guinovart C, Aguilar R, et al. High production of pro - inflammatory cytokines by maternal blood mononuclear cells is associated with reduced maternal malaria but increased cord blood infection. Malar J [Internet]. 2018;1-13. Available from: https://doi.org/10.1186/s12936-018-2317-2

188. Requena P, Barrios D, Robinson LJ, Samol P, Umbers AJ, Wangnapi R, et al. Proinflammatory responses and higher IL-10 production by $\mathrm{T}$ cells correlate with protection against malaria during pregnancy and delivery outcomes. $\mathrm{J}$ Immunol [Internet]. 2015 Apr 1;194(7):3275-85. Available from: http://www.ncbi.nlm.nih.gov/pubmed/25725110

189. El-Shazly S, Makhseed M, Azizieh F, Raghupathy R. Increased Expression of Pro-Inflammatory Cytokines in Placentas of Women Undergoing Spontaneous Preterm Delivery or Premature Rupture of Membranes. Am J Reprod Immunol. $2004 \mathrm{Jul} ; 52(1): 45-52$.

190. Arababadi MK, Aminzadeh F, Hassanshahi G, Khorramdelazad H, Norouzi M, Zarandi ER, et al. Cytokines in Preterm Delivery. Lab Med. 2012 May;43(4):27-30.

191. Romero R, Espinoza J, Gonçalves LF, Kusanovic JP, Friel LA, Nien JK. Inflammation in preterm and term labour and delivery. Semin Fetal Neonatal Med. 2006 Oct;11(5):317-26.

192. Riley JK, Nelson DM. Toll-like receptors in pregnancy disorders and placental dysfunction. Clin Rev Allergy Immunol. 2010;39(3):185-93. 
193. Ilievski V, Lu S-J, Hirsch E. Activation of Toll-like Receptors 2 or 3 and Preterm Delivery in the Mouse. Reprod Sci. 2007 May;14(4):315-20.

194. Harris J, Lang T, Thomas JPW, Sukkar MB, Nabar NR, Kehrl JH. Autophagy and inflammasomes. Mol Immunol [Internet]. 2017 Jun;86:10-5. Available from: http://linkinghub.elsevier.com/retrieve/pii/S0161589017300524

195. Samie M, Lim J, Verschueren E, Baughman JM, Peng I, Wong A, et al. Selective autophagy of the adaptor TRIF regulates innate inflammatory signaling. Nat Immunol [Internet]. 2018 Mar 22;19(3):246-54. Available from: http://dx.doi.org/10.1038/s41590-017-0042-6

196. Olivier M, Van Den Ham K, Shio MT, Kassa FA, Fougeray S. Malarial Pigment Hemozoin and the Innate Inflammatory Response. Front Immunol [Internet]. 2014;5(February):1-10. Available from: http://journal.frontiersin.org/article/10.3389/fimmu.2014.00025/abstract

197. Kalantari P, DeOliveira RB, Chan J, Corbett Y, Rathinam V, Stutz A, et al. Dual engagement of the NLRP3 and AIM2 inflammasomes by plasmodium-derived hemozoin and DNA during malaria. Cell Rep [Internet]. 2014 Jan 16;6(1):196210. Available from: http://dx.doi.org/10.1016/j.celrep.2013.12.014

198. Ataide MA, Andrade WA, Zamboni DS, Wang D, Souza M do C, Franklin BS, et al. Malaria-induced NLRP12/NLRP3-dependent caspase-1 activation mediates inflammation and hypersensitivity to bacterial superinfection. PLoS Pathog [Internet]. $2014 \quad$ Jan;10(1):e1003885. Available from: http://www.ncbi.nlm.nih.gov/pubmed/24453977

199. Agrawal V, Jaiswal MK, Mallers T, Katara GK, Gilman-Sachs A, Beaman KD, et al. Altered autophagic flux enhances inflammatory responses during inflammation-induced preterm labor. Sci Rep [Internet]. 2015 Mar 23;5:9410. Available from: http://www.nature.com/doifinder/10.1038/srep09410

200. Oh S-Y, Choi S-J, Kim KH, Cho EY, Kim J-H, Roh C-R. Autophagy-related proteins, LC3 and Beclin-1, in placentas from pregnancies complicated by preeclampsia. Reprod Sci. 2008;15(9):912-20.

201. Shi C-S, Kehrl JH. MyD88 and Trif target Beclin 1 to trigger autophagy in macrophages. J Biol Chem [Internet]. 2008 Nov 28;283(48):33175-82. Available from: http://www.ncbi.nlm.nih.gov/pubmed/18772134

202. Eskelinen EL, Saftig P. Autophagy: a lysosomal degradation pathway with a central role in health and disease. Biochim Biophys Acta [Internet]. 2009;1793(4):664-73. Available from: http://www.ncbi.nlm.nih.gov/pubmed/18706940

203. Gong J-S, Kim GJ. The role of autophagy in the placenta as a regulator of cell death. Luty AJF, editor. Clin Exp Reprod Med [Internet]. 2014 Sep 10;41(3):97-107. Available
http://dx.plos.org/10.1371/journal.pone.0187291

from:

204. Mizushima N, Yoshimori T. How to Interpret LC3 Immunoblotting ND RIB ND ES SC RIB. Autophagy [Internet]. 2007;3(December):4-7. Available from: http://www.tandfonline.com.proxy.library.adelaide.edu.au/doi/abs/10.4161/auto. 4600 
205. Harris J, Hartman M, Roche C, Zeng SG, O'Shea A, Sharp FA, et al. Autophagy controls IL-1 $\beta$ secretion by targeting Pro-IL-1 $\beta$ for degradation. J Biol Chem. 2011;286(11):9587-97.

206. Prokesch A, Blaschitz A, Bauer T, Moser G, Hiden U, Zadora J, et al. Placental DAPK1 and autophagy marker LC3B-II are dysregulated by TNF- $\alpha$ in a gestational age-dependent manner. Histochem Cell Biol [Internet]. 2017 Jun 17;147(6):695-705. Available from: http://link.springer.com/10.1007/s00418016-1537-1

207. Dimasuay KG, Gong L, Rosario F, McBryde E, Spelman T, Glazier J, et al. Impaired placental autophagy in placental malaria. Luty AJF, editor. PLoS One [Internet]. $2017 \quad$ Nov 10;12(11):e0187291. Available from: http://dx.plos.org/10.1371/journal.pone.0187291 